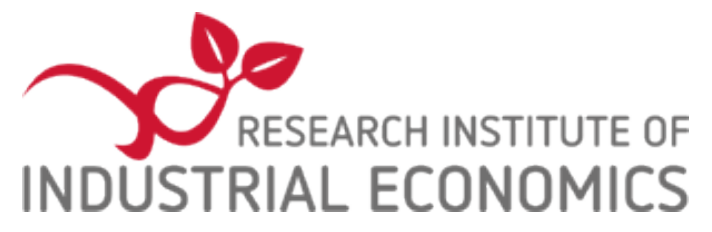

IFN Working Paper No. 1158, 2017

\title{
Production or Transmission Investments? A Comparative Study
}

Mario Blázquez de Paz 


\title{
Production or Transmission Investments? A Comparative Analysis*
}

\author{
Mario Blazquez de Paz ${ }^{\dagger}$
}

This version: March 10, 2017

\begin{abstract}
A successful transformation to a carbon neutral energy system requires the correct investments in transmission and production capacity. In a zonal pricing electricity market, the one proposed by the European Commission to integrate the European electricity markets, I analyze the effects that investments in transmission and production capacity have on consumer welfare and suppliers' profits. In the specific setting of this paper, I show that when the competition is perfect, an investment in transmission capacity between zones (inter Transmission System Operator (TSO) investment) and an investment in production capacity generate the same equilibrium outcome allocations. In contrast, when the competition is imperfect, an inter TSO investment and an investment in production capacity generate different equilibrium outcome allocations.
\end{abstract}

KEYWORDS: electricity auctions, wholesale electricity markets, transmission capacity constraints, investment transmission capacity, investment production capacity, energy economics.

JEL codes: D43, D44, L13, L94

\footnotetext{
*I am very grateful to Giacomo Calzolari and Emanuele Tarantino for comments and excellent supervision during my Ph.D. I am also very grateful for fruitful discussions and comments from Ola Andersson, Claude Crampes, Oscar Erixson, Shon Ferguson, Pär Holmberg, Henrik Horn, Ewa Lazarczyk, ThomasOlivier Léautier, Chloé Le Coq, Pehr-Johan Norbäck, Andy Philpott, Michele Polo, Mar Reguant, Andrew Rodes, Keith Ruddell, Rune Stenbacka, Thomas Tangerås, Nils-Henrik von der Fehr, workshop participants at CREE (Oslo), Swedish Workshop on Competition Research (Swedish Competition Authority), Toulouse School of Economics and Vaxholm (Stockholm), seminar participants at Bologna University, Complutense University, Norwegian School of Economics, Research Institute of Industrial Economics (IFN), Salamanca University and conference participants at Energy Economics Iberian Conference, Industrial Organization: Theory, Empirics and Experiments and Mannheim Energy Conference. This research was completed within the framework of the IFN research program "The Economics of Electricity Markets". I acknowledge financial support from the Jan Wallander and Tom Hedelius Foundation, the Torsten Söderberg Foundation and the Swedish Energy Agency. Simon Ek helped me translate parts of the paper into Swedish. Christina Lönnblad helped me proofread the paper.

${ }^{\dagger}$ Research Institute of Industrial Economics. Mail: mario.blazquezdepaz@ifn.se
} 


\section{Introduction}

Governed by the ambitious European climate and energy goals, the European countries are increasing the investments in renewable production capacity (Energinet, 2015; ENTSO-E, 2010; EWIS, 2010). To accommodate renewable production capacity into the electricity system, and to deal with the problems derived from the volatility of this type of energy, the European Union is increasing its investments in transmission capacity to improve the integration of the electricity markets within the European Union (Energinet, 2015; ENTSO-E, 2014; European Commission, 2013; Svenska Kraftnät, 2015). In that context, the European Network of Transmission System Operators for Electricity identifies four types of investments necessary to promote the proper functioning of electricity markets: Investments in transmission capacity between zones (inter TSO investments); investments in transmission capacity within the same zone (intra TSO investments); investments in transmission capacity to connect isolated renewable production capacity with the electricity grid; and production capacity investments (ENTSO-E, 2014).

In the specific setting of this paper, when the competition is perfect, I show that inter TSO investments and production capacity investments have the same effects on consumers welfare and suppliers' profits. In contrast, when the competition is imperfect, consumers welfare and suppliers' profits are different depending on the type of investment.

The imperfect competition case is represented by a simple duopoly model similar to that in Fabra et al. (2006). There are two different nodes ("North" and "South") that are connected through a transmission line with a limited transmission capacity, 1 where both nodes belong to the same zone, i.e., the equilibrium price in both nodes is the same even when the transmission line is congested. Suppliers are symmetric in production capacity and asymmetric in marginal costs, where the efficient supplier is located in node North, and the inefficient supplier is located in node South. Each supplier faces a perfectly inelastic demand in each node, which is known with certainty when the suppliers submit their offer prices. The assumption of price-inelastic demand can be justified by the fact that the vast majority of consumers purchase electricity under regulated prices that are independent of the prices set in the wholesale market, at least in the short run.

In the inter TSO investment model, the TSO invests in a new transmission line that connects node North with a perfectly competitive electricity zone with an equilibrium price lower than the marginal costs of the inefficient supplier, i.e., the electricity flows from an electricity zone with low equilibrium prices. This set up captures the investment configuration proposed by ENTSO-E (2014), where the transmission line connects electricity markets with different equilibrium prices. In the production capacity investment model, it does not exist a transmission line that connect node North with an outside zone. Instead, an entrant with marginal costs equal to the equilibrium price in the outside zone in the inter TSO investment model invests in production capacity in node North.

In a uniform price auction such as those used in the majority of European countries (e.g., Nord Pool or Italy), the suppliers submit a single price offer for its entire capacity ${ }^{2}$

\footnotetext{
${ }^{1}$ The term "transmission capacity constraint" is used throughout this article in the electrical engineering sense: a transmission line is constrained when the flow of power is equal to the capacity of the line, as determined by engineering standards.

${ }^{2}$ Fabra et al. (2006) show that the equilibrium outcome allocation may not change when firms submit
} 
As in Bjørndal and Jørnsten (2001) and Bjørndal and Jørnsten (2007), I work out the equilibrium taking into account the transmission constraints. Therefore, it is not necessary to introduce any type of redispatch mechanism to alleviate transmission constraints ${ }^{3}$

In the specific setting of this paper, when the competition is perfect, the equilibrium outcome is the same irrespective of the type of investment. When the competition is imperfect, the inter TSO investment model outperforms the production capacity investment model by maximizing consumers welfare because of two different effects: The "size effect," and the "competition effect."

To explain the differences in equilibrium prices between both models. I proceed in two steps. First, to explain the "size effect," I assume that the supplier that enter in node North in the production capacity investment model behaves competitively, i.e., it behaves as the supplier located in the outside zone in the inter TSO investment model. Therefore, I can isolate the impact that an increase in transmission capacity has on equilibrium prices. In the inter TSO investment model, the total demand is larger than in the production capacity investment model since it comprises the demand in nodes North, South, and in addition, it also includes the demand in the outside zone. When the size of the market is large, the efficient supplier finds more profitable to satisfy the total demand, and extract the efficiency rents by submitting a low bid. Therefore, due to the size effect, the equilibrium prices in the inter TSO investment model are lower or equal than in the production capacity investment model.

Second, to explain the "competition effect," I assume that the supplier that enter in node North in the production capacity investment model behaves strategically by submitting its own bid that is higher or equal than its marginal costs. If the investment in production capacity is high enough, the supplier that invests in production capacity faces a high residual demand, and it can find profitable to submit the maximum bid allowed by the auctioneer inducing an increase in the equilibrium prices. Therefore, due to the competition effect, the equilibrium prices in the inter TSO investment model are lower or equal than in the production capacity investment model.

Therefore, in this paper, I can disentangle if the reduction in equilibrium prices in the inter TSO investment model is due to an increase in the size of the market, or is due to an increase in competition.

The inter TSO investment model outperforms the capacity investment model by maximizing suppliers' profits only when the demand is low. When the demand is low, the efficient supplier submits the lower bid, and the equilibrium prices are low in both models. However, in the inter TSO investment model, the size of the market is larger, and so they are suppliers' profits. When the demand is high, the equilibrium price in nodes North and South is higher than in the outside zone, and the electricity flows from the outside zone

single price offers for their entire capacity and when they submit a set of price-quantity offers.

${ }^{3}$ If the transmission constraint is not taken into account to characterize the equilibrium, as soon as the transmission line is congested in a zonal pricing electricity market, some type of redispatch must be introduced to avoid congestion in the transmission line. The supplier located in the the exporting node must reduce its production and the one located in the importing node must increase its production to avoid congestion in the transmission line. The redispatch can follow a market based mechanism (Belgium, Finland, France or Sweden) or a cost based mechanism (Austria, Switzerland, or Germany). 
to node North. Therefore, the size of the market is the same in both models. However, due to the competition effect, the equilibrium prices in the capacity investment model are equal or higher than in the inter TSO investment model, and so they are suppliers' profits.

In annex two, I characterize the equilibrium in the intra TSO investment model, and I compare that model with the inter TSO investment and the production capacity investment models. In the comparisons between the intra TSO investment model and the other two models, it is not possible to establish a clear rank in terms of consumers welfare and suppliers' profits.

In their seminal papers, Bohn et al. (1984), Hogan (1992), Wu et al. (1996) and Chao and Peck (1996) characterize the equilibrium in a perfect competitive nodal pricing electricity market. Adding more structure to those models, Bjørndal and Jørnsten (2001) characterize the equilibrium in a zonal pricing electricity market and analyze the effect of different bidding zone configurations on equilibrium outcome allocations. Holmberg and Lazarczyk (2015) compare the equilibrium performance between nodal pricing electricity markets, zonal pricing electricity markets with counter-trading, and discriminatory pricing in large games with many producers and certain information. They conclude that the three market designs result in the same efficient dispatch, but that the zonal pricing with counter-trading results in additional payments to producers in export-constrained nodes, which leads to inefficient investments in the long run. Following a similar approach, Green (2007) works out the equilibrium using different pricing rules, and he concludes that moving from uniform prices to optimal nodal prices could raise welfare by $1.3 \%$ of the generator revenues, and would be less vulnerable to market power. I work out the equilibrium in a zonal pricing electricity market when competition is imperfect.

I also contribute to the literature that analyzes the benefits of integrating electricity markets. Green (2010) analyzes the accommodation of renewable capacity in the UK electricity market, proposing that the price of power must vary across the country, reflecting the true state of the transmission system and giving incentives to reduce generation and investment in constrained areas. Green et al. (2010) evaluate the impact of intermittent wind generation on hourly equilibrium prices and output, using data on expected wind generation capacity and demand for 2020. Ehrenmann et al. (2005) analyze the design of efficient congestion management systems to remove the obstacles to cross-border trade of electricity in Europe. Grimm et al. (2006) analyze the investment in transmission and generation capacity considering the cases of one vs. multiple price zones, and analyzing different approaches to recovering network costs (lump-sum, generation capacity and energy based fees). Newbery et al. (2015) estimate the potential benefit to the EU of coupling inter-connectors to increase the efficiency of trading day-ahead, intra-day and sharing balancing services efficiently across borders. They estimate that the gains could be as high as 3.3 euros billion/yr. Neuhoff et al. (2011) explore the benefits of the most efficient form of market integration via nodal pricing, and they include a large volume $(125 G W)$ of predicted future wind connection into the analysis. They find savings of $1.1-3.6 \%$ of the variable operating costs. Leuthold et al. (2005) compare the results of different pricing systems in the German electricity sector, and they find that the welfare under nodal pricing exceeds the welfare under cost minimization by $0.9 \%$ on average; moreover, they also find that the accommodation of offshore wind leads to a significant welfare gain. 
In a context of imperfect competition, there also exists a wide literature that characterizes the equilibrium in an electricity market in the presence of transmission constraints. Borenstein et al. (2000) characterize the equilibrium in an electricity network where suppliers compete in quantities as in a Cournot game. Neuhoff et al. (2005) analyze the robustness of three numerical models of transmission-constrained electricity markets, and they conclude that the results coincide under competitive conditions, but in the Cournot case, the predicted prices differ significantly. Holmberg and Philpott (2012) solve for symmetric supply function equilibria in electricity networks when demand is uncertain ex-ante. Escobar and Jofré (2010) analyze the effect of transmission losses and transmission costs on equilibrium outcome allocations, but they neglect transmission constraints.

Dijk and Willems (2011) work out the equilibrium in a zonal electricity market introducing a market based redispatch mechanism, and following Joskow and Tirole's (2000) approach, they assume that demand is concentrated to only one node. Therefore, they model the investments in transmission capacity to connect isolated renewable production capacity with the electricity grid (one of the four investments identified by the European Network of Transmission System Operators for Electricity to guarantee the proper integration of electricity markets). In contrast to Dijk and Willems (2011), I work out the equilibrium in a zonal electricity market when there is demand in both nodes; moreover, I consider the effects of an increase in production capacity, and also the effects of an increase in transmission capacity on consumer welfare and suppliers' profits. Therefore, I characterize the equilibrium in the other three investments identified by the European Network of Transmission System Operators for Electricity to guarantee the correct integration of electricity markets.

The article proceeds as follows. Section 2 describes the inter TSO investment model, and the production capacity investment model. Section 3 characterizes the equilibrium. Section 4 concludes the paper. The analysis of the intra TSO investment model, and the proofs are in the Appendix.

\section{Model}

\subsection{Inter TSO investment model}

Set up of the model (figure 1). There exists a zonal pricing electricity market with two electricity nodes, node North and node South, that are connected by a transmission line with capacity $T$.

There exist two duopolists with capacities $k_{n}$ and $k_{s}$, where subscript $n$ means that the supplier is located in node North and subscript $s$ means that the supplier is located in node South. The suppliers' marginal costs of production are $c_{n}$ and $c_{s}$ for production levels less than the capacity, while production above the capacity is impossible (i.e., infinitely costly). Suppliers are symmetric in capacity $k_{n}=k_{s}=k>0$ and asymmetric in production costs, where $c=c_{s}>c_{n}=0.4$ The level of demand in any period, $\theta_{n}$ in node

\footnotetext{
${ }^{4}$ In this paper, I analyze the effect that an increase in transmission and production capacity have on equilibrium prices. In order to introduce variation on equilibrium prices, and to analyze the effect of those policies on consumers welfare and suppliers' profits, I assume that one of the suppliers is more
} 
North and $\theta_{s}$ in node South, is independent across nodes and independent of price, i.e., perfectly inelastic. Moreover, $\theta_{i} \in\left[\underline{\theta}_{i}, \bar{\theta}_{i}\right] \subseteq[0, k+T], i=n, s$.

Figure 1: Inter TSO investment model, Production capacity investment model

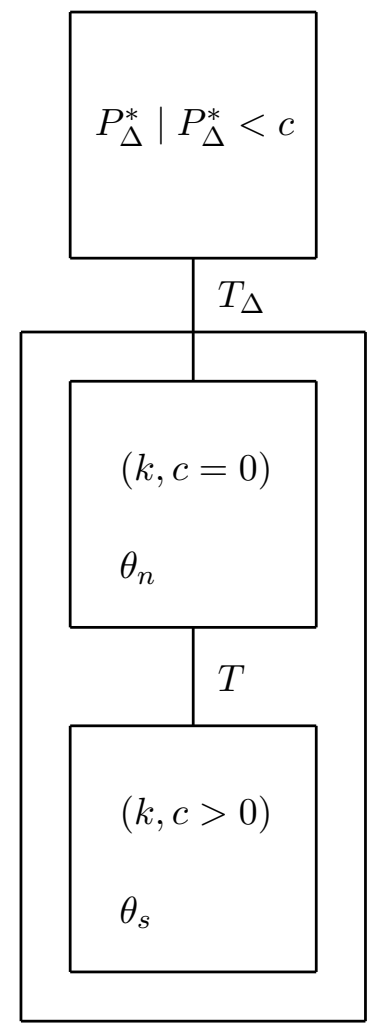

Inter TSO model

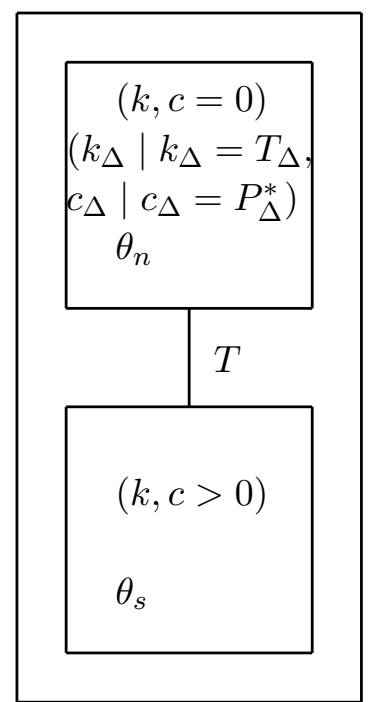

Production capacity model

The capacity of the transmission line that connects nodes North and South can be lower than the installed capacity in each node $T \leq k$, i.e., the transmission line could be congested for some realization of demands $\left(\theta_{s}, \theta_{n}\right)$.

In addition, the Transmission System Operator invests in a new transmission line with capacity $T_{\Delta}$ that connects node North to a competitive electricity zone with equilibrium price $\left(P_{\Delta}^{*} \mid P_{\Delta}^{*}<c\right)$, i.e., the electricity flows from an electricity zone with low equilibrium prices. Moreover, the supplier located in the outside zone (supplier $\Delta$ ) does not have production capacity installed in the zone that includes nodes North and South, and it does not participate in the auction; therefore, $\left(P_{\Delta}^{*}\right)$ is taken as a parameter by suppliers $n$ and $s 5$

Timing of the game. First, I explain the imperfect competition case. Having observed the realization of demands $\theta \equiv\left(\theta_{s}, \theta_{n}\right)$, each supplier simultaneously and independently submits a bid specifying the minimum price at which it is willing to supply up to its capacity, $b_{i} \leq P, i=n, s$, where $P$ denotes the "market reserve price", possibly deter-

efficient than the other. This is a standard assumption in this type of models (Deneckere and Kovenock, 1996; Fabra et al., 2006).

${ }^{5}$ In the next section, I present a model in which a supplier $\Delta$ invests in production capacity in node North and, in that case, supplier $\Delta$ participates in the auction by submitting its own bids. 
Figure 2: Inter TSO investment model. Supplier n's outcome and profits
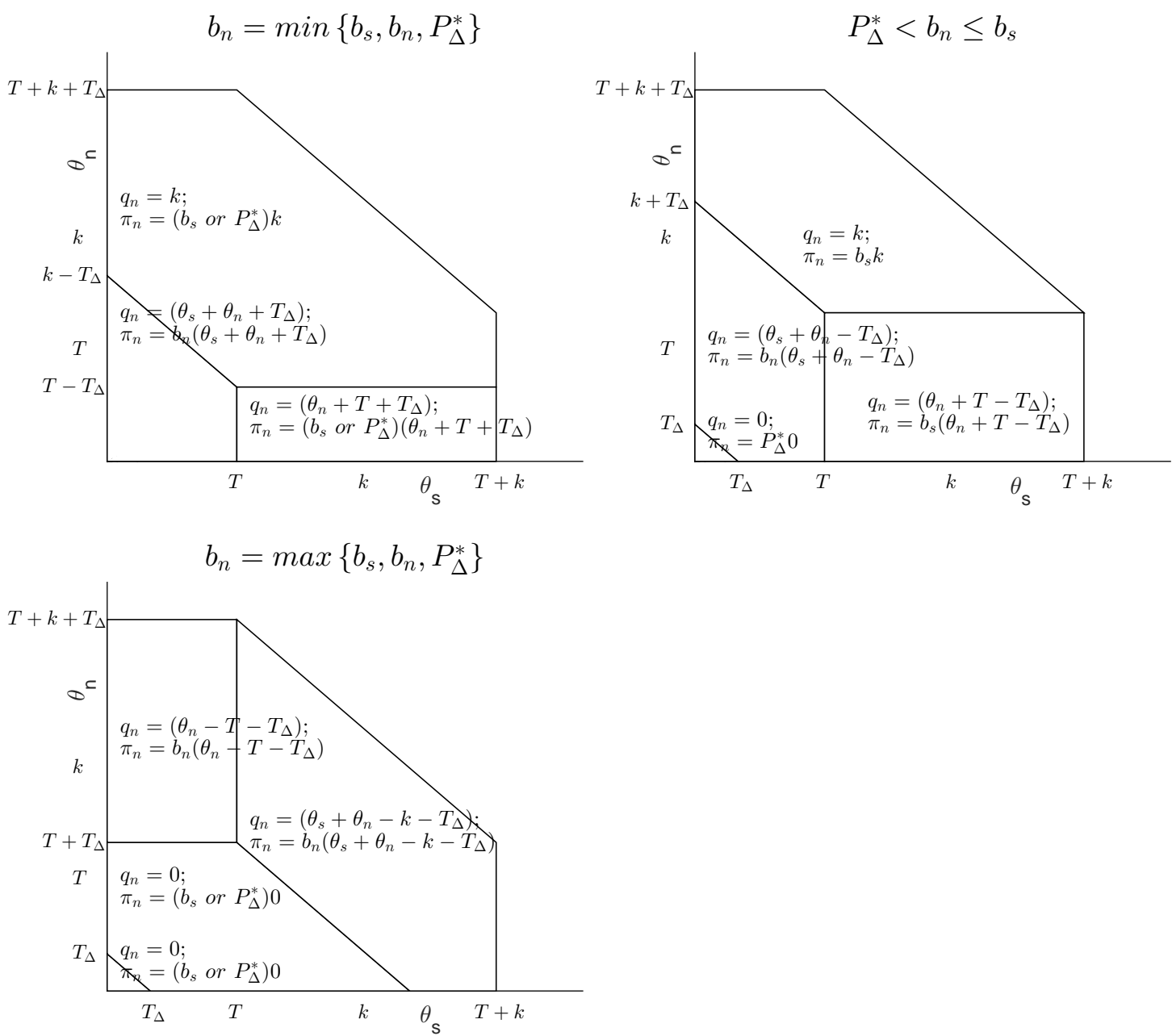

mined by regulation. ${ }^{6}$ Let $b \equiv\left(b_{s}, b_{n}\right)$ denote a bid profile. On basis of this profile, the auctioneer calls suppliers into operation. If suppliers submit different bids, the capacity of the lower-bidding supplier is dispatched first. If the capacity of the lower-bidding supplier is not sufficient to satisfy total demand, the higher-bidding supplier's capacity is then dispatched to serve residual demand. If the two suppliers submit equal bids, the efficient supplier, supplier $n$, is ranked first. 7

In the inter TSO investment model, suppliers $n$ and $s$ are the only ones that participate in the auction. Therefore, I explain only supplier $n$ 's and $s$ 's output and profit functions.

The output allocated to supplier $n$, denoted by $q_{n}\left(b ; \theta, k, T, T_{\Delta}\right)$, is given by

\footnotetext{
${ }^{6} \mathrm{P}$ can be interpreted as the price at which all consumers are indifferent between consuming and not consuming, or a price cap imposed by the regulatory authorities. See von der Fehr and Harbord (1993).

${ }^{7}$ The tie-breaking rule minimizes the production costs, and it is in line with the tie-breaking rules used in the literature (Fabra et al. (2006)).
} 
$q_{n}\left(b ; \theta, k, T, T_{\Delta}\right)= \begin{cases}\min \left\{\theta_{s}+\theta_{n}+T_{\Delta}, \theta_{n}+T+T_{\Delta}, k\right\} & \text { if } b_{n}=\min \left\{b_{n}, b_{s}, P_{\Delta}^{*}\right\} \\ \max \left\{0, \min \left\{\theta_{s}+\theta_{n}-T_{\Delta}, \theta_{n}+T-T_{\Delta}, k\right\}\right\} & \text { if } P_{\Delta}^{*}<b_{n} \leq b_{s} \\ \max \left\{0, \theta_{n}-T-T_{\Delta}, \theta_{s}+\theta_{n}-k-T_{\Delta}\right\} & \text { if } b_{n}=\max \left\{b_{n}, b_{s}, P_{\Delta}^{*}\right\}\end{cases}$

The demand that can be satisfied by supplier $n$ when it submits the lower bid $b_{n}=$ $\min \left\{b_{s}, b_{n}, P_{\Delta}^{*}\right\}$ is defined by $\min \left\{\theta_{s}+\theta_{n}+T_{\Delta}, \theta_{n}+T+T_{\Delta}, k\right\}$. The realization of $\left(\theta_{s}, \theta_{n}\right)$ determines three different areas (left-hand upper panel in figure 2). When demand is low and the transmission line that connects nodes North and South is not congested, supplier $n$ satisfies total demand in both nodes and demand in zone Delta $\left(\theta_{s}+\theta_{n}+T_{\Delta}\right)$. If the demand in node South is larger than the transmission capacity that connects nodes North and South $\theta_{s}>T$, supplier $n$ can satisfy the demand in node South only up to the transmission capacity; therefore, the total demand that supplier $n$ can satisfy is $\left(\theta_{n}+T+T_{\Delta}\right)$. When demand is high enough, supplier $n$ sells its entire production capacity $(k)$.

The demand that can be satisfied by supplier $n$ when it submits the intermediate bid $\left(P_{\Delta}^{*}<b_{n} \leq b_{s}\right)$ is defined by $\max \left\{0, \min \left\{\theta_{s}+\theta_{n}-T_{\Delta}, \theta_{n}+T-T_{\Delta}, k\right\}\right\}$. The realization of $\left(\theta_{s}, \theta_{n}\right)$ determines four different areas (right-hand upper panel in figure 2). Given that $P_{\Delta}^{*}<b_{n}$, the electricity flows from zone Delta to the zone that includes nodes North and South; therefore, when the demand in nodes North and South is lower than the transmission capacity that connects zone Delta with node North, supplier $n$ 's residual demand is zero. As soon as demand is larger than the transmission capacity that connects zone Delta with node North, supplier $n$ satisfies the demand that cannot be satisfied by supplier $\Delta\left(\theta_{s}+\theta_{n}-T_{\Delta}\right)$. If demand in node South is larger than the transmission capacity that connects nodes North and South $\theta_{s}>T$, supplier $n$ can satisfy the demand in node South only up to the transmission capacity; therefore, the total demand that supplier $n$ can satisfy is $\left(\theta_{n}+T-T_{\Delta}\right)$. When demand is high enough, supplier $n$ sells its entire production capacity $(k)$.

The demand that can be satisfied by supplier $n$ when it submits the higher bid $b_{n}=\max \left\{b_{n}, b_{s}, P_{\Delta}^{*}\right\}$ is defined by $\max \left\{0, \theta_{n}-T-T_{\Delta}, \theta_{s}+\theta_{n}-k-T_{\Delta}\right\}$. The realization of $\left(\theta_{s}, \theta_{n}\right)$ determines four different areas (left-hand bottom panel in figure 2). When demand in both nodes is low enough, and the transmission line that connects nodes North and South is not congested, demand is satisfied by suppliers $s$ and $\Delta$; therefore, supplier $n$ 's residual demand is zero. As soon as the transmission line that connect nodes North and South is congested, some residual demand $\left(\theta_{n}-T-T_{\Delta}\right)$ remains for supplier $n$. When total demand is large enough, suppliers $s$ and $\Delta$ cannot satisfy total demand, and some residual demand $\left(\theta_{s}+\theta_{n}-k-T_{\Delta}\right)$ remains for supplier $n$.

The output allocated to supplier $s$, denoted by $q_{s}\left(b ; \theta, k, T, T_{\Delta}\right)$, is given by

$q_{s}\left(b ; \theta, k, T, T_{\Delta}\right)= \begin{cases}\max \left\{0, \min \left\{\theta_{s}+\theta_{n}-T_{\Delta}, \theta_{s}+T-T_{\Delta}, k\right\}\right\} & \text { if } P_{\Delta}^{*}<b_{s}<b_{n} \\ \max \left\{0, \theta_{s}-T, \theta_{s}+\theta_{n}-k-T_{\Delta}\right\} & \text { if } b_{s}=\max \left\{b_{n}, b_{s}, P_{\Delta}^{*}\right\}\end{cases}$

The demand that can be satisfied by supplier $s$ when it submits the bid $\left(P_{\Delta}^{*}<b_{s}<b_{n}\right)$ is defined by $\max \left\{0, \min \left\{\theta_{s}+\theta_{n}-T_{\Delta}, \theta_{s}+T-T_{\Delta}, k\right\}\right\}$. The realization of $\left(\theta_{s}, \theta_{n}\right)$ determines four different areas (left-hand panel in figure 3). Supplier $s$ never submits a bid 
Figure 3: Inter TSO investment model. Supplier $s$ 's outcome and profits
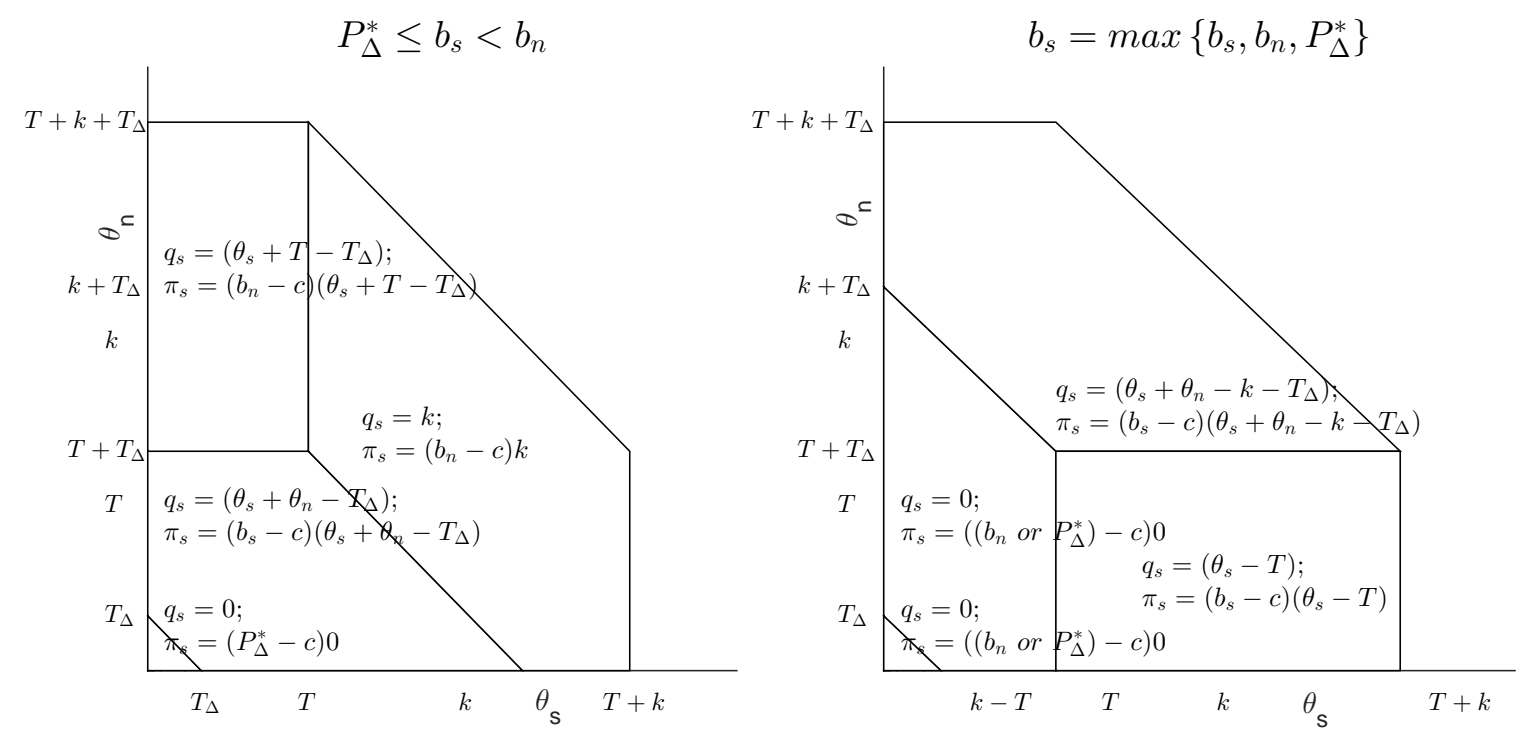

lower than its marginal costs. Moreover, given that $P_{\Delta}^{*}<c$, electricity flows from zone Delta to the zone that includes nodes North and South; therefore, when the demand in nodes North and South is lower than the transmission capacity that connects zone Delta with node North, supplier s's residual demand is zero. As soon as the demand is larger than the transmission capacity that connects zone Delta with node North, supplier $s$ satisfies the demand that cannot be satisfied by supplier $\Delta\left(\theta_{s}+\theta_{n}-T_{\Delta}\right)$. If the demand in node North is larger than the transmission capacity that connects nodes North and South $\theta_{n}>T$, supplier $s$ can satisfy the demand in node North only up to the transmission capacity; therefore, the total demand that supplier $s$ can satisfy is $\left(\theta_{s}+T-T_{\Delta}\right)$. When demand is high enough, supplier $s$ sells its entire production capacity $(k)$.

The demand that can be satisfied by supplier $s$ when it submits the higher bid $b_{s}=\max \left\{b_{n}, b_{s}, P_{\Delta}^{*}\right\}$ is defined by $\max \left\{0, \theta_{s}-T, \theta_{s}+\theta_{n}-k-T_{\Delta}\right\}$. The realization of $\left(\theta_{s}, \theta_{n}\right)$ determines four different areas (right-hand panel in figure 3 ). When demand in both nodes is low enough, and the transmission line that connects nodes North and South is not congested, demand is satisfied by suppliers $n$ and $\Delta$; therefore, supplier $s$ 's residual demand is zero. As soon as the transmission line that connects nodes North and South is congested, some residual demand $\left(\theta_{s}-T\right)$ remains for supplier $s$. When total demand is large enough, supplier $n$ and $\Delta$ cannot satisfy total demand and some residual demand $\left(\theta_{s}+\theta_{n}-k-T_{\Delta}\right)$ remains for supplier $s$.

The payments are worked out by the auctioneer. For a given realization of $\theta \equiv\left(\theta_{s}, \theta_{n}\right)$ and a bid profile $b \equiv\left(b_{s}, b_{n}\right)$, supplier $n$ 's profits are expressed as 


$$
\begin{aligned}
& \pi_{n}^{u}\left(b ; \theta, k, T, T_{\Delta}\right)= \\
& \begin{cases}b_{n}\left(\theta_{s}+\theta_{n}+T_{\Delta}\right) & \text { if } b_{n}=\min \left\{b_{n}, b_{s}, P_{\Delta}^{*}\right\} \text { and } \\
& \left(\theta_{s} \leq T \text { and } \theta_{s}+\theta_{n} \leq k-T_{\Delta}\right) \\
\left(b_{s} \text { or } P_{\Delta}^{*}\right) \min \left\{\theta_{n}+T+T_{\Delta}, k\right\} & \text { if } b_{n}=\min \left\{b_{n}, b_{s}, P_{\Delta}^{*}\right\} \text { and } \\
& \left(\theta_{s}>T \text { or } \theta_{s}+\theta_{n}>k-T_{\Delta}\right) \\
P_{\Delta}^{*}(0) & \text { if } P_{\Delta}^{*}<b_{n} \leq b_{s} \text { and } \theta_{s}+\theta_{n} \leq T_{\Delta} \\
b_{n}\left(\theta_{s}+\theta_{n}-T_{\Delta}\right) & \text { if } P_{\Delta}^{*}<b_{n} \leq b_{s} \text { and } \theta_{s}+\theta_{n}>T_{\Delta} \text { and } \\
& \left(\theta_{s} \leq T \text { and } \theta_{s}+\theta_{n} \leq k+T_{\Delta}\right) \\
b_{s} \min \left\{\theta_{n}+T-T_{\Delta}, k\right\} & \text { if } P_{\Delta}^{*}<b_{n} \leq b_{s} \text { and } \\
& \left(\theta_{s}>T \text { or } \theta_{s}+\theta_{n}>k+T_{\Delta}\right) \\
\left(b_{s} \text { or } P_{\Delta}^{*}\right)(0) & \text { if } b_{n}=\max \left\{b_{n}, b_{s}, P_{\Delta}^{*}\right\} \text { and } \\
& \left(\theta_{n}<T+T_{\Delta}, \theta_{s} \in(0, T)\right. \text { and } \\
& \left.\theta_{s}+\theta_{n}<k+T_{\Delta}, \theta_{s} \in\left(T, k+T_{\Delta}\right)\right) \\
b_{n} \max \left\{\theta_{n}-T-T_{\Delta}, \theta_{s}+\theta_{n}-k-T_{\Delta}\right\} & \text { if } b_{n}=\max \left\{b_{n}, b_{s}, P_{\Delta}^{*}\right\} \text { and } \\
& \left(\theta_{n}>T+T_{\Delta}, \theta_{s} \in(0, T)\right. \text { or } \\
& \left.\theta_{s}+\theta_{n}>k+T_{\Delta}, \theta_{s} \in\left(T, k+T_{\Delta}\right)\right)\end{cases}
\end{aligned}
$$

I explain the payoff function in detail. If $b_{n}=\min \left\{b_{n}, b_{s}, P_{\Delta}^{*}\right\}$ and $\left(\theta_{s} \leq T\right.$ and $\left.\theta_{s}+\theta_{n} \leq k-T_{\Delta}\right)$, supplier $n$ submits the lower bid in the auction, the transmission line is not congested and supplier $n$ has enough capacity to satisfy total demand; therefore, supplier $n$ sets the price and satisfies total demand. When $b_{n}=\min \left\{b_{n}, b_{s}, P_{\Delta}^{*}\right\}$ and $\left(\theta_{s}>T\right.$ or $\left.\theta_{s}+\theta_{n}>k-T_{\Delta}\right)$, supplier $n$ submits the lower bid in the auction, the transmission line that connects nodes North and South is congested, or supplier $n$ does not have enough capacity to satisfy total demand; therefore, suppliers $s$ or $\Delta$ are called into operation, the equilibrium price is $b_{s}$ or $P_{\Delta}^{*}$, and supplier $n$ sells its production capacity (up to the transmission line capacity) at the price set by any of the other suppliers (left-hand upper panel, figure 2).

If $P_{\Delta}^{*}<b_{n} \leq b_{s}$ and $\theta_{s}+\theta_{n} \leq T_{\Delta}$, the equilibrium price in zone Delta is lower than supplier $n$ 's bid, and the transmission line that connects zone Delta with node North is not congested; therefore, the electricity flows from zone Delta, the equilibrium price in nodes North and South is $P_{\Delta}^{*}$, and supplier $n$ 's residual demand is zero. If $P_{\Delta}^{*}<b_{n} \leq b_{s}$ and $\theta_{s}+\theta_{n}>T_{\Delta}$ and $\left(\theta_{s} \leq T\right.$ and $\left.\theta_{s}+\theta_{n} \leq k+T_{\Delta}\right)$, the electricity that flows from zone Delta is not enough to satisfy the demand in nodes North and South; therefore, supplier $n$ faces a positive residual demand, sets the price and satisfies the demand that cannot be satisfied by supplier $\Delta$. If $P_{\Delta}^{*}<b_{n} \leq b_{s}$ and $\left(\theta_{s}>T\right.$ or $\left.\theta_{s}+\theta_{n}>k+T_{\Delta}\right)$, supplier $s$ faces a positive residual demand, sets the price, and supplier $n$ sells its production capacity (up to the transmission line capacity) at the price set by supplier $s$ (right-hand upper panel, figure 2).

If $b_{n}=\max \left\{b_{n}, b_{s}, P_{\Delta}^{*}\right\}$ and $\left(\theta_{n}<T+T_{\Delta}, \theta_{s} \in(0, T)\right.$ and $\theta_{s}+\theta_{n}<k+T_{\Delta}, \theta_{s} \in$ $\left.\left(T, k+T_{\Delta}\right)\right)$, supplier $n$ submits the higher bid in the auction, the transmission line that connects nodes North and South is not congested and suppliers $s$ and $\Delta$ have enough capacity to satisfy total demand; therefore, the equilibrium price is $b_{s}$ or $P_{\Delta}^{*}$, and supplier 
$n$ 's residual demand is zero. When $b_{n}=\max \left\{b_{n}, b_{s}, P_{\Delta}^{*}\right\}$ and $\left(\theta_{n}>T+T_{\Delta}, \theta_{s} \in(0, T)\right.$ or $\left.\theta_{s}+\theta_{n}>k+T_{\Delta}, \theta_{s} \in\left(T, k+T_{\Delta}\right)\right)$, supplier $n$ submits the higher bid in the auction, the transmission line that connects nodes North and South is congested, or suppliers $s$ and $\Delta$ do not have enough capacity to satisfy total demand; therefore, supplier $n$ is called into operation, sets the price, and satisfies the residual demand (left-hand bottom panel, figure 2].

Supplier s's profits are expressed as

$$
\begin{aligned}
& \pi_{s}^{u}\left(b ; \theta, k, T, T_{\Delta}\right)= \\
& \begin{cases}\left(P_{\Delta}^{*}-c\right)(0) & \text { if } P_{\Delta}^{*}<b_{s} \leq b_{n} \text { and } \theta_{s}+\theta_{n} \leq T_{\Delta} \\
\left(b_{s}-c\right)\left(\theta_{s}+\theta_{n}-T_{\Delta}\right) & \text { if } P_{\Delta}^{*}<b_{s} \leq b_{n} \text { and } \theta_{s}+\theta_{n}>T_{\Delta} \\
& \text { and }\left(\theta_{n}<T+T_{\Delta}, \theta_{s} \in(0, T)\right. \text { and } \\
& \left.\theta_{s}+\theta_{n}<k+T_{\Delta}, \theta_{s} \in\left(T, k+T_{\Delta}\right)\right) \\
\left(b_{n}-c\right) \min \left\{\theta_{s}+T-T_{\Delta}, k\right\} & \text { if } P_{\Delta}^{*}<b_{s} \leq b_{n} \\
& \text { and }\left(\theta_{n}>T+T_{\Delta}, \theta_{s} \in(0, T)\right. \text { or } \\
& \left.\theta_{s}+\theta_{n}>k+T_{\Delta}, \theta_{s} \in\left(T, k+T_{\Delta}\right)\right) \\
& \text { if } b_{s}=\max \left\{b_{s}, b_{n}, P_{\Delta}^{*}\right\} \text { and } \\
\left(\left(b_{n} \text { or } P_{\Delta}^{*}\right)-c\right)(0) & \left(\theta_{s}+\theta_{n} \leq k+T_{\Delta} \text { and } \theta_{s} \leq T\right) \\
& \text { if } b_{s}=\max \left\{b_{s}, b_{n}, P_{\Delta}^{*}\right\} \text { and } \\
\left(b_{s}-c\right) \max \left\{\theta_{s}-T, \theta_{s}+\theta_{n}-k-T_{\Delta}\right\} & \left(\theta_{s}+\theta_{n}>k+T_{\Delta} \text { or } \theta_{s}>T\right)\end{cases}
\end{aligned}
$$

Given that $c>P_{\Delta}^{*}$, supplier $s$ cannot submit a bid lower than $P_{\Delta}^{*}$; therefore, it can only be dispatched second or last in the auction. If $P_{\Delta}^{*}<b_{s} \leq b_{n}$ and $\theta_{s}+\theta_{n} \leq T_{\Delta}$, supplier $s$ 's bid is lower than supplier $n$ 's bid, the transmission line that connects zone Delta to node North is not congested and the supplier located in zone Delta satisfies total demand; therefore, the equilibrium price in nodes North and South is $P_{\Delta}^{*}$ and supplier s's residual demand is zero. If $P_{\Delta}^{*}<b_{s} \leq b_{n}$ and $\theta_{s}+\theta_{n}>T_{\Delta}$ and $\left(\theta_{n}<T+T_{\Delta}, \theta_{s} \in(0, T)\right.$ and $\left.\theta_{s}+\theta_{n}<k+T_{\Delta}, \theta_{s} \in\left(T, k+T_{\Delta}\right)\right)$, supplier $s$ faces a positive residual demand, sets the price and satisfies the demand in both nodes minus the demand that is satisfied by the supplier located in zone Delta. If $P_{\Delta}^{*}<b_{s} \leq b_{n}$ and $\left(\theta_{n}>T+T_{\Delta}, \theta_{s} \in(0, T)\right.$ or $\left.\theta_{s}+\theta_{n}>k+T_{\Delta}, \theta_{s} \in\left(T, k+T_{\Delta}\right)\right)$, suppliers $\Delta$ and $s$ do not have enough production capacity to satisfy demand, or the transmission line that connects both nodes is congested; therefore, supplier $n$ faces a positive residual demand, sets the price, and supplier $s$ sells its production capacity (up to the transmission line capacity) at the price set by supplier $n$ (left-hand panel, figure 3).

If $b_{s}=\max \left\{b_{s}, b_{n}, P_{\Delta}^{*}\right\}$ and $\left(\theta_{s}+\theta_{n} \leq k+T_{\Delta}\right.$ and $\left.\theta_{s} \leq T\right)$, supplier $s$ submits the higher bid in the auction, the transmission line is not congested and suppliers $n$ and $\Delta$ have enough capacity to satisfy total demand; therefore, the equilibrium price is $b_{s}$ or $P_{\Delta}^{*}$ and supplier $s$ 's residual demand is zero. When $b_{s}=\max \left\{b_{s}, b_{n}, P_{\Delta}^{*}\right\}$ and $\left(\theta_{s}+\theta_{n}>k+T_{\Delta}\right.$ or $\theta_{s}>T$ ), supplier $s$ submits the higher bid in the auction, the transmission line that connects both nodes is congested, or suppliers $n$ and $\Delta$ do not have enough capacity to satisfy total demand; therefore, supplier $s$ is called into operation, sets the price and satisfies the residual demand (right-hand bottom panel, figure 3). 
In the perfect competition case. The suppliers submit a bid equal to their marginal cost. The efficient supplier (supplier $n$ ) is dispatched first, and its output is denoted by $q_{n}\left(b ; \theta, k, T, T_{\Delta}\right)=\min \left\{\theta_{s}+\theta_{n}+T_{\Delta}, \theta_{n}+T+T_{\Delta}, k\right\}$. The inefficient supplier is dispatched last, and its output is denoted by $q_{s}\left(b ; \theta, k, T, T_{\Delta}\right)=\max \left\{0, \theta_{s}-T, \theta_{s}+\theta_{n}-k-T_{\Delta}\right\}$. Suppliers' profits are equal to:

$$
\begin{aligned}
& \pi_{n}\left(b ; \theta, k, T, T_{\Delta}\right)= \begin{cases}b_{n}\left(\theta_{s}+\theta_{n}+T_{\Delta}\right) & \text { if } \theta_{s} \leq T, \text { and } \theta_{s}+\theta_{n} \leq k-T_{\Delta} \\
\left(b_{s} \text { or } P_{\Delta}^{*}\right) \min \left\{\theta_{n}+T+T_{\Delta}, k\right\} & \text { otherwise }\end{cases} \\
& \pi_{s}\left(b ; \theta, k, T, T_{\Delta}\right)= \begin{cases}b_{s} \max \left\{\theta_{s}-T, \theta_{s}+\theta_{n}-k-T_{\Delta}\right\} & \text { if } \theta_{s}>T, \text { or } \theta_{s}+\theta_{n}>k+T_{\Delta} \\
\left(b_{n} \text { or } P_{\Delta}^{*}\right)(0) & \text { otherwise }\end{cases}
\end{aligned}
$$

Given that supplier $n$ submits the lower bid, it is dispatched first and sets the price when it has enough production capacity to satisfy the demand, and when the transmission line that connects nodes North and South is not congested. Otherwise, suppliers $s$, or $\Delta$ are called into operation setting the price, and satisfying the residual demand.

\subsection{Production capacity investment model}

Set up of the model (figure 1). In contrast with the inter TSO model, it doesn't exist a transmission line that connects node North with an outside zone. Instead, an entrant (supplier $\Delta$ ) with production capacity $\left(k_{\Delta} \mid k_{\Delta}=T_{\Delta}\right)$ and marginal costs equal to the equilibrium price in the outside zone $\left(c_{\Delta} \mid c_{\Delta}=P_{\Delta}^{*}<c\right)$ invests in production capacity in node North. Moreover, the supplier $\Delta$ has production capacity installed in node North, and it participates in the zone that includes nodes North and South by submitting its own bid in the auction. This is in contrast to the inter TSO investment model, where supplier $\Delta$ does not participate in the zone that includes nodes North and South, i.e., the equilibrium price in zone Delta, $\left(P_{\Delta}^{*}\right)$, is taken as a parameter by suppliers $n$ and $s$.

This set up gives us the opportunity to compare the inter TSO investment and the production capacity investment models, since in both cases the investments in transmission (production) are the same, and the equilibrium price (marginal costs) are the same.

Timing of the game. First, I explain the imperfect competition case. The timing is the same as in the inter TSO investment model. The output allocated to supplier $n$ is very similar to the output allocated to that supplier in the inter TSO investment model except for the fact that supplier $n$ cannot sell part of its production capacity in an outside zone. Therefore, I focus on the output functions of the two other suppliers. The output allocated to supplier $s$ denoted by $q_{s}\left(b ; \theta, T, k, k_{\Delta}\right)$, is given by

$$
q_{s}\left(b ; \theta, T, k, k_{\Delta}\right)= \begin{cases}\min \left\{\theta_{s}+\theta_{n}, \theta_{s}+T, k\right\} & \text { if } b_{s}=\min \left\{b_{s}, b_{n}, b_{\Delta}\right\} \\ \max \left\{0, \min \left\{\theta_{s}-T, \theta_{s}+\theta_{n}-k, k\right\}\right\} & \text { if } b_{n} \leq b_{s}<b_{\Delta} \\ \max \left\{0, \min \left\{\theta_{s}+\theta_{n}-k_{\Delta}, \theta_{s}+T-k_{\Delta}, k\right\}\right\} & \text { if } b_{\Delta} \leq b_{s}<b_{n} \\ \max \left\{0, \theta_{s}-T, \theta_{s}+\theta_{n}-k-k_{\Delta}\right\} & \text { if } b_{s}=\max \left\{b_{s}, b_{n}, b_{\Delta}\right\}\end{cases}
$$

The demand that can be satisfied by supplier $s$ when it submits the lower bid $b_{s}=$ $\min \left\{b_{s}, b_{n}, b_{\Delta}\right\}$ is defined by $\min \left\{\theta_{s}+\theta_{n}, \theta_{s}+T, k\right\}$. The realization of $\left(\theta_{s}, \theta_{n}\right)$ determines three different areas (left-hand upper panel in figure 4 ). When demand is low and 
Figure 4: Production capacity investment model. Supplier s's outcome and profits
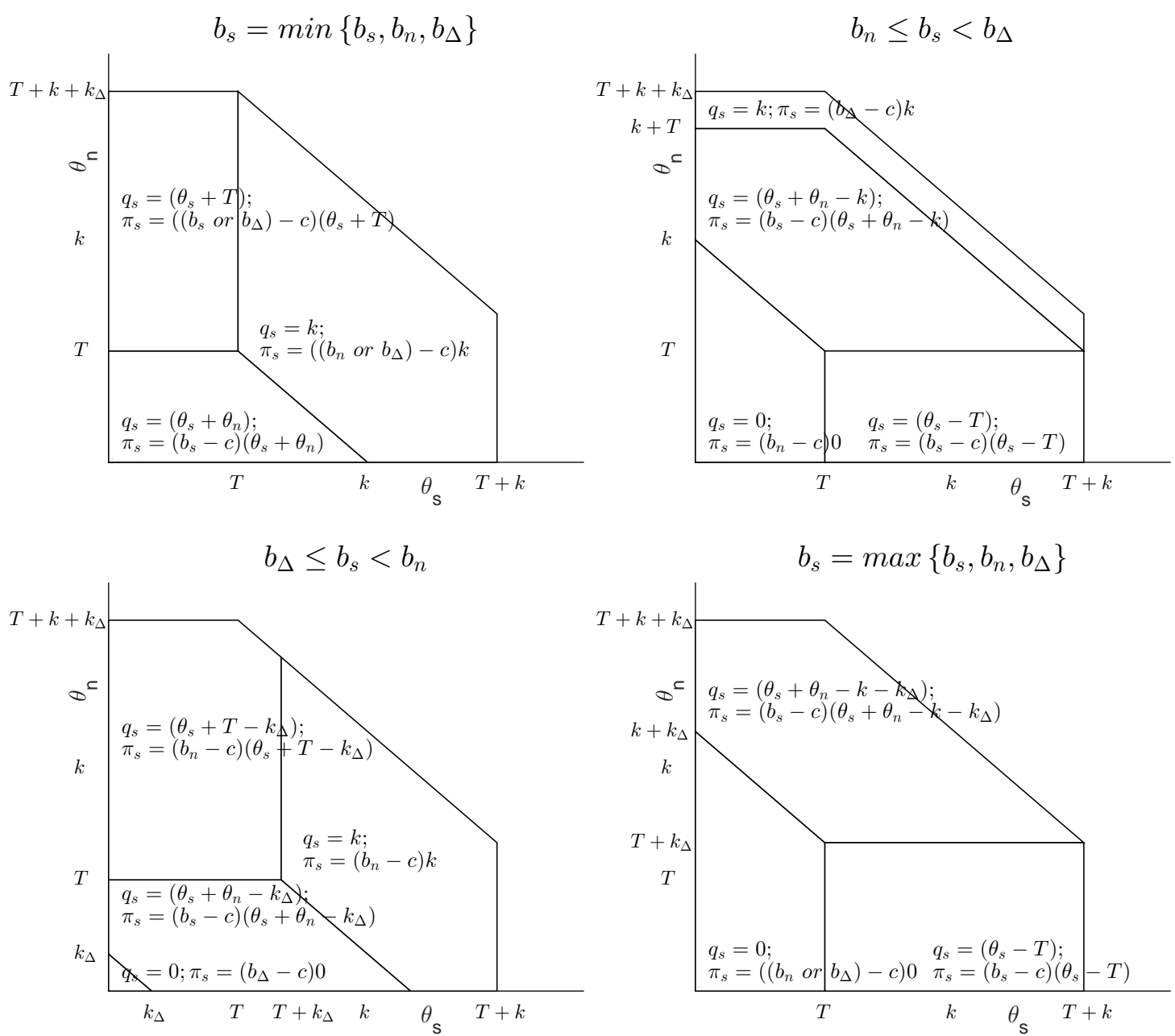

the transmission line is not congested, supplier $s$ satisfies total demand in both nodes $\left(\theta_{s}+\theta_{n}\right)$. If the demand in node North is larger than the transmission capacity that connects both nodes $\theta_{n}>T$, supplier $s$ satisfies the demand in node North only up to the transmission capacity; therefore, the total demand that supplier $s$ can satisfy is $\left(\theta_{s}+T\right)$. When demand is high enough, supplier $s$ sells its entire production capacity $(k)$.

The demand that can be satisfied by supplier $s$ when it submits the intermediate bid $b_{n} \leq b_{s}<b_{\Delta}$ is defined by $\max \left\{0, \min \left\{\theta_{s}-T, \theta_{s}+\theta_{n}-k, k\right\}\right\}$. The realization of $\left(\theta_{s}, \theta_{n}\right)$ determines four different areas (right-hand upper panel in figure 4). Given that $b_{n} \leq b_{s}<b_{\Delta}$, supplier $n$ is dispatched first in the auction; therefore, when the demand in nodes North and South is lower than supplier n's production capacity, and the transmission line is not congested, supplier $s$ 's residual demand is zero. As soon as the demand in node South is larger than the transmission capacity $\theta_{s}>T$, the demand in node South cannot be satisfied by supplier $n$ and some residual demand $\left(\theta_{s}-T\right)$ remains for supplier $s$. When total demand is high, supplier $n$ cannot satisfy total demand and some residual demand $\left(\theta_{s}+\theta_{n}-k\right)$ remains for supplier $s$. When demand is high enough, supplier $s$ sells its entire production capacity $(k)$.

The demand that can be satisfied by supplier $s$ when it submits the intermediate bid 
$b_{\Delta} \leq b_{s}<b_{n}$ is defined by $\max \left\{0, \min \left\{\theta_{s}+\theta_{n}-k_{\Delta}, \theta_{s}+T-k_{\Delta}, k\right\}\right\}$. The realization of $\left(\theta_{s}, \theta_{n}\right)$ determines four different areas (left-hand bottom panel in figure 4). Given that $b_{\Delta} \leq b_{s}<b_{n}$, supplier $\Delta$ is dispatched first in the auction; therefore, when the demand in nodes North and South is lower than supplier $\Delta$ 's production capacity, supplier s's residual demand is zero. As soon as the demand is larger than supplier $\Delta$ 's production capacity, supplier $s$ satisfies the demand that cannot be satisfied by supplier $\Delta\left(\theta_{s}+\theta_{n}-k_{\Delta}\right)$. If the demand in node North is larger than the transmission capacity that connects both nodes $\theta_{n}>T$, supplier $s$ can satisfy the demand in node North only up to the transmission capacity; therefore, the total demand that supplier $s$ can satisfy is $\left(\theta_{s}+T-k_{\Delta}\right)$. When demand is high enough, supplier $s$ sells its entire production capacity $(k)$.

The demand that can be satisfied by supplier $s$ when it submits the higher bid $b_{s}=\max \left\{b_{n}, b_{s}, P_{\Delta}^{*}\right\}$ is defined by $\max \left\{0, \theta_{s}-T, \theta_{s}+\theta_{n}-k-k_{\Delta}\right\}$. The realization of $\left(\theta_{s}, \theta_{n}\right)$ determines three different areas (right-hand bottom panel in figure 4). When demand in both nodes is low enough, and the transmission line is not congested, demand is satisfied by suppliers $n$ and $\Delta$; therefore, supplier $s$ 's residual demand is zero. As soon as the demand in node South is larger than the transmission capacity, the demand in node South cannot be satisfied by suppliers $n$ and $\Delta$ and thus, some residual demand $\left(\theta_{s}-T\right)$ remains for supplier $s$. When total demand is large enough, suppliers $n$ and $\Delta$ cannot satisfy total demand and some residual demand $\left(\theta_{s}+\theta_{n}-k-k_{\Delta}\right)$ remains for supplier $s$.

The output allocated to supplier $\Delta$ denoted by $q_{\Delta}\left(b ; \theta, T, k, k_{\Delta}\right)$ is given by

$q_{\Delta}\left(b ; \theta, T, k, k_{\Delta}\right)= \begin{cases}\min \left\{\theta_{s}+\theta_{n}, k_{\Delta}\right\} & \text { if } b_{\Delta}=\min \left\{b_{s}, b_{n}, b_{\Delta}\right\} \\ \max \left\{0, \min \left\{\theta_{s}+\theta_{n}-k, \theta_{n}+T-k, k_{\Delta}\right\}\right\} & \text { if } b_{n} \leq b_{\Delta}<b_{s} \\ \max \left\{0, \min \left\{\theta_{n}-T, \theta_{s}+\theta_{n}-k, k_{\Delta}\right\}\right\} & \text { if } b_{s}<b_{\Delta} \leq b_{n} \\ \max \left\{0, \theta_{n}-T-k, \theta_{s}+\theta_{n}-2 k\right\} & \text { if } b_{\Delta}=\max \left\{b_{s}, b_{n}, b_{\Delta}\right\}\end{cases}$

The demand that can be satisfied by supplier $\Delta$ when it submits the lower bid $b_{\Delta}=\min \left\{b_{n}, b_{s}, b_{\Delta}\right\}$ is defined by $\min \left\{\theta_{s}+\theta_{n}, k_{\Delta}\right\}$. The realization of $\left(\theta_{s}, \theta_{n}\right)$ determines two different areas (left-hand upper panel in figure 5). When demand is low, supplier $\Delta$ satisfies total demand in both nodes $\left(\theta_{s}+\theta_{n}\right)$. When demand is high enough, supplier $\Delta$ sells its entire production capacity $\left(k_{\Delta}\right)$.

The demand that can be satisfied by supplier $\Delta$ when it submits the intermediate bid $b_{n} \leq b_{\Delta}<b_{s}$ is defined by $\max \left\{0, \min \left\{\theta_{s}+\theta_{n}-k, \theta_{n}+T-k, k_{\Delta}\right\}\right\}$. The realization of $\left(\theta_{s}, \theta_{n}\right)$ determines three different areas (right-hand upper panel in figure 5). Given that $b_{n} \leq b_{\Delta}<b_{s}$, supplier $n$ is dispatched first in the auction; therefore, when the demand in nodes North and South is lower than supplier n's production capacity, supplier $\Delta$ 's residual demand is zero. Moreover, due to the transmission constraint, even when supplier $\Delta$ 's bid is lower than supplier s's bid, as soon as the demand in node South is larger than the transmission capacity, supplier $\Delta$ 's residual demand is also zero. As soon as demand is larger than supplier $n$ 's production capacity, supplier $\Delta$ satisfies the demand that cannot be satisfied by supplier $n\left(\min \left\{\theta_{s}+\theta_{n}-k, \theta_{n}+T-k\right\}\right)$. When demand is high enough, supplier $\Delta$ sells its entire production capacity $\left(k_{\Delta}\right)$.

The demand that can be satisfied by supplier $\Delta$ when it submits the intermediate bid $b_{s}<b_{\Delta} \leq b_{n}$ is defined by $\max \left\{0, \min \left\{\theta_{n}-T, \theta_{s}+\theta_{n}-k, k_{\Delta}\right\}\right\}$. The realization of 
Figure 5: Production capacity investment model. Supplier $\Delta$ 's outcome and profits
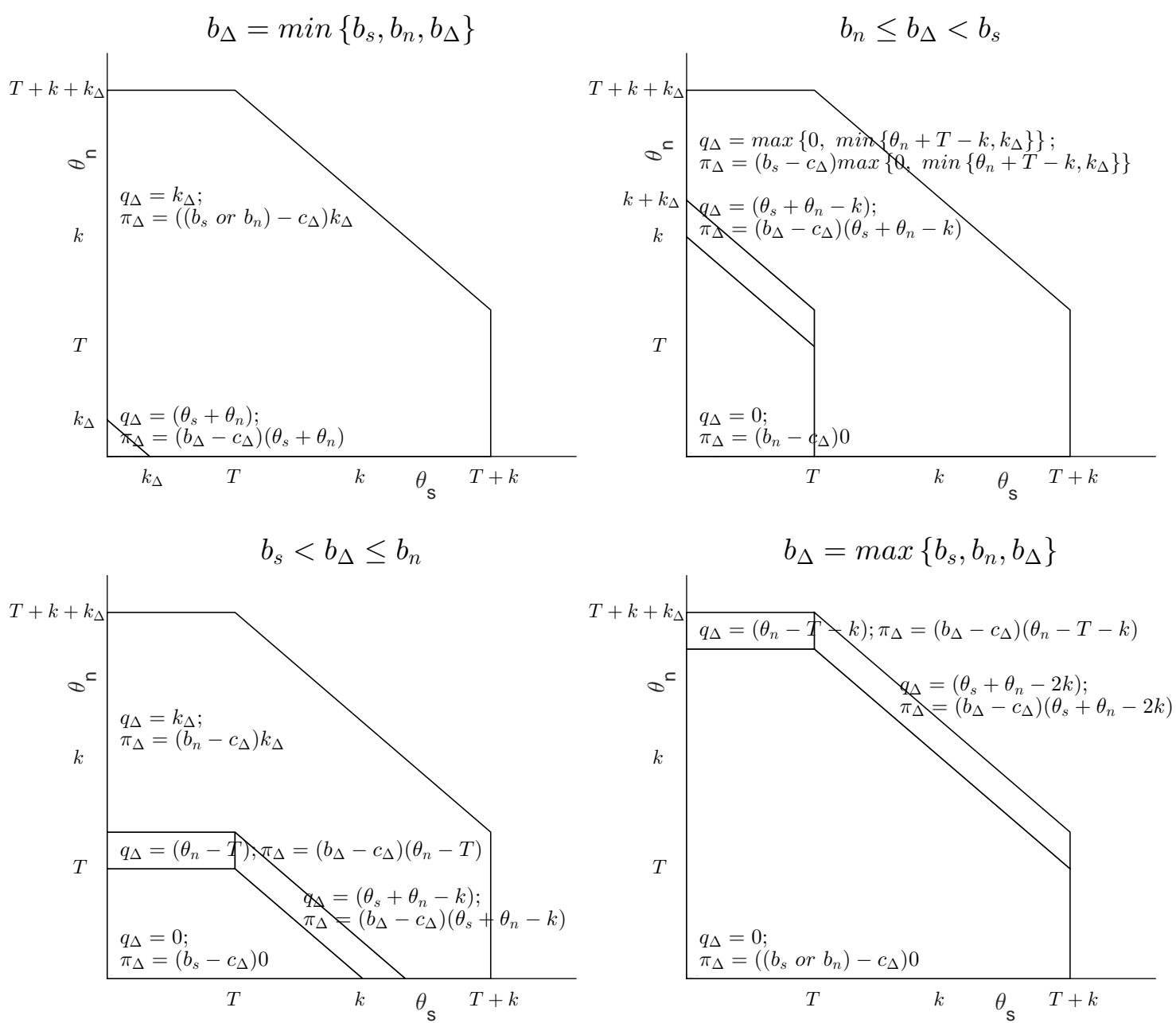

$\left(\theta_{s}, \theta_{n}\right)$ determines four different areas (left-hand bottom panel in figure 5). Given that $b_{s}<b_{\Delta} \leq b_{n}$, supplier $s$ is dispatched first in the auction; therefore, when the demand in nodes North and South is lower than supplier s's production capacity, and the transmission line is not congested, supplier $\Delta$ 's residual demand is zero. When the transmission line is congested, or supplier $s$ does not have enough capacity to satisfy total demand, supplier $\Delta$ satisfies the demand that cannot be satisfied by supplier $s\left(\min \left\{\theta_{n}-T, \theta_{s}+\theta_{n}-k\right\}\right)$. When demand is high enough, supplier $\Delta$ sells its entire production capacity $\left(k_{\Delta}\right)$.

The demand that can be satisfied by supplier $\Delta$ when it submits the higher bid $b_{\Delta}=\max \left\{b_{s}, b_{n}, b_{\Delta}\right\}$ is defined by $\max \left\{0, \theta_{n}-T-k, \theta_{s}+\theta_{n}-2 k\right\}$. The realization of $\left(\theta_{s}, \theta_{n}\right)$ determines three different areas (right-hand bottom panel in figure 5). When demand in both nodes is low, demand is satisfied by suppliers $n$ and $s$; therefore, supplier $\Delta$ 's residual demand is zero. As soon as suppliers $n$ and $s$ cannot satisfy total demand, some residual demand $\min \left\{\theta_{n}-T-k, \theta_{s}+\theta_{n}-2 k\right\}$ remains for supplier $\Delta$.

The payments are worked out by the auctioneer. For a given realization of $\theta \equiv\left(\theta_{s}, \theta_{n}\right)$ and a bid profile $b \equiv\left(b_{s}, b_{n}, b_{\Delta}\right)$, supplier $s$ 's profits are expressed as 

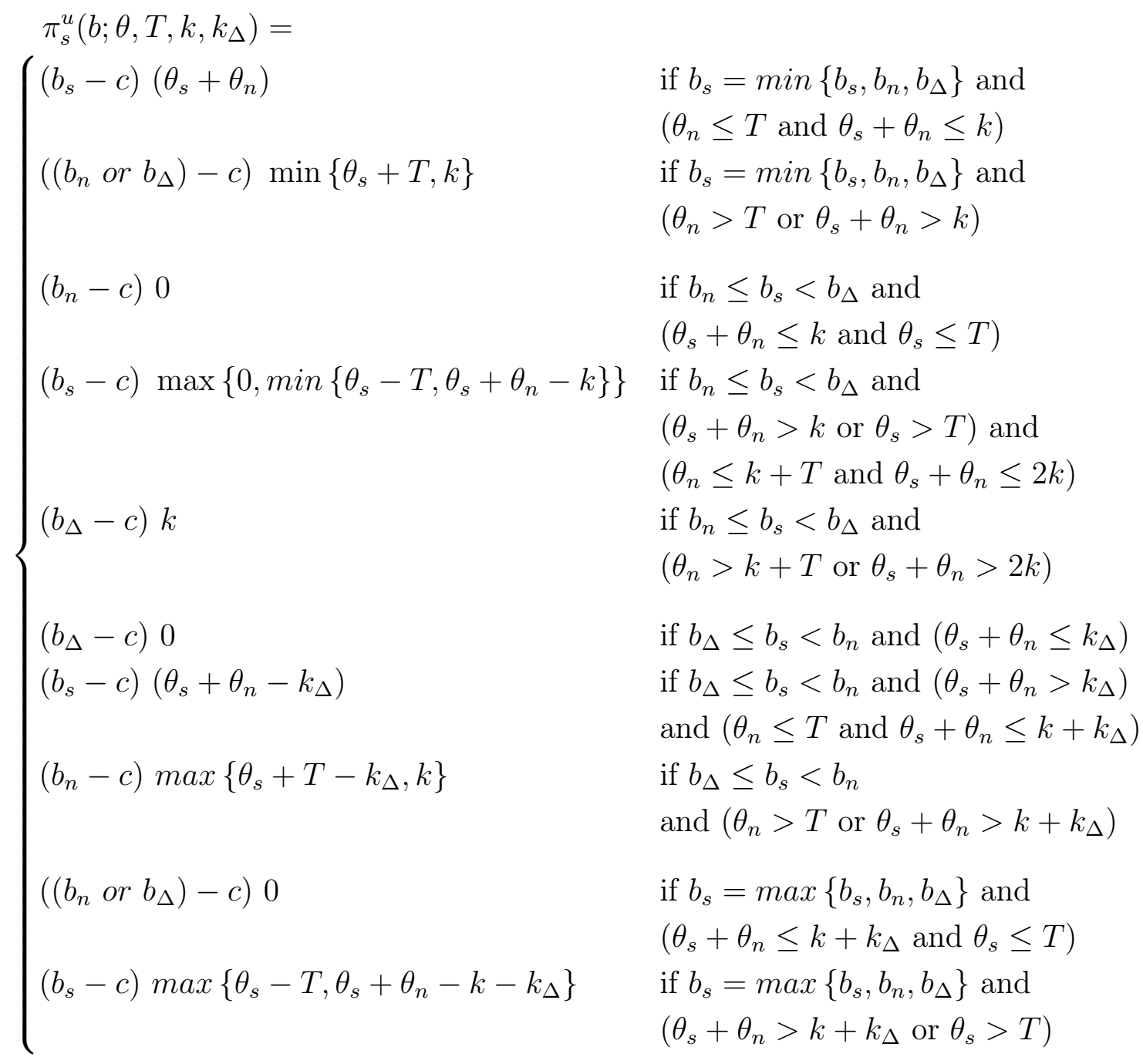

I explain the payoff function in detail. If $b_{s}=\min \left\{b_{s}, b_{n}, b_{\Delta}\right\}$ and $\left(\theta_{n} \leq T\right.$ and $\left.\theta_{s}+\theta_{n} \leq k\right)$, supplier $s$ submits the lower bid in the auction, the transmission line is not congested and it has enough capacity to satisfy total demand; therefore, supplier $s$ sets the price and satisfies total demand. When $b_{s}=\min \left\{b_{s}, b_{n}, b_{\Delta}\right\}$ and $\left(\theta_{n}>T\right.$ or $\left.\theta_{s}+\theta_{n}>k\right)$, supplier $s$ submits the lower bid in the auction, the transmission line is congested, or supplier $s$ does not have enough capacity to satisfy total demand; therefore, suppliers $n$ or $\Delta$ are called into operation, set the price, and supplier $s$ sells its production capacity (up to the transmission line capacity) at the price set by any of the other suppliers (left-hand upper panel, figure 4).

If $b_{n} \leq b_{s}<b_{\Delta}$ and $\left(\theta_{s}+\theta_{n} \leq k\right.$ and $\left.\theta_{s} \leq T\right)$, supplier $n$ 's bid is lower than supplier $s$ 's bid, supplier $n$ has enough capacity to satisfy the demand and the transmission line is not congested; therefore, supplier $n$ sets the price and supplier $s$ 's residual demand is zero. If $b_{n} \leq b_{s}<b_{\Delta}$ and $\left(\theta_{s}+\theta_{n}>k\right.$ or $\left.\theta_{s}>T\right)$ and $\left(\theta_{n} \leq k+T\right.$ and $\left.\theta_{s}+\theta_{n} \leq 2 k\right)$, the transmission line is congested, or supplier $n$ does not have enough capacity to satisfy total demand; therefore, supplier $s$ faces a positive residual demand, sets the price and satisfies the demand that cannot be satisfied by supplier $n$. If $b_{n} \leq b_{s}<b_{\Delta}$ and $\left(\theta_{n}>k+T\right.$ or $\theta_{s}+\theta_{n}>2 k$ ), supplier $\Delta$ faces a positive residual demand, sets the price, and supplier $s$ sells its production capacity at the price set by supplier $\Delta$ (right-hand upper panel, figure 
4).

If $b_{\Delta} \leq b_{s}<b_{n}$ and $\left(\theta_{s}+\theta_{n} \leq k_{\Delta}\right)$, supplier $\Delta$ 's bid is lower than supplier $s$ 's bid, supplier $\Delta$ has enough capacity to satisfy the demand and the transmission line is not congested; therefore, supplier $\Delta$ sets the price and supplier $s$ 's residual demand is zero. If $b_{\Delta} \leq b_{s}<b_{n}$ and $\left(\theta_{s}+\theta_{n}>k_{\Delta}\right)$ and $\left(\theta_{n} \leq T\right.$ and $\left.\theta_{s}+\theta_{n} \leq k+k_{\Delta}\right)$, supplier $\Delta$ does not have enough production capacity to satisfy the demand; therefore, supplier $s$ faces a positive residual demand, sets the price and satisfies the demand that cannot be satisfied by supplier $\Delta$. If $b_{\Delta} \leq b_{s}<b_{n}$ and $\left(\theta_{n}>T\right.$ or $\left.\theta_{s}+\theta_{n}>k+k_{\Delta}\right)$, supplier $n$ faces a positive residual demand, sets the price, and supplier $s$ sells its production capacity at the price set by supplier $n$ (left-hand bottom panel, figure 4).

If $b_{s}=\max \left\{b_{s}, b_{n}, b_{\Delta}\right\}$ and $\left(\theta_{s}+\theta_{n} \leq k+k_{\Delta}\right.$ and $\left.\theta_{s} \leq T\right)$, supplier $s$ submits the higher bid in the auction, the transmission line is not congested, and suppliers $n$ and $\Delta$ have enough capacity to satisfy total demand; therefore, suppliers $n$ or $\Delta$ set the price, and supplier $s$ 's residual demand is zero. When $b_{s}=\max \left\{b_{s}, b_{n}, b_{\Delta}\right\}$ and $\left(\theta_{s}+\theta_{n}>k+k_{\Delta}\right.$ or $\left.\theta_{s}>T\right)$, supplier $s$ submits the higher bid in the auction, the transmission line is congested, or suppliers $n$ and $\Delta$ do not have enough capacity to satisfy total demand; therefore, supplier $s$ is called into operation, sets the price and satisfies the residual demand (right-hand bottom panel, figure 4).

Supplier $\Delta$ 's profits are expressed as 


$$
\begin{aligned}
& \pi_{\Delta}^{u}\left(b ; \theta, T, k, k_{\Delta}\right)= \\
& \left(\left(b_{\Delta}-c_{\Delta}\right)\left(\theta_{s}+\theta_{n}\right) \quad \text { if } b_{\Delta}=\min \left\{b_{s}, b_{n}, b_{\Delta}\right\}\right. \text { and } \\
& \left(\theta_{s}+\theta_{n} \leq k_{\Delta}\right) \\
& \left(\left(b_{n} \text { or } b_{s}\right)-c_{\Delta}\right) k_{\Delta} \quad \text { if } b_{\Delta}=\min \left\{b_{s}, b_{n}, b_{\Delta}\right\} \text { and } \\
& \left(\theta_{s}+\theta_{n}>k_{\Delta}\right) \\
& \left(b_{n}-c_{\Delta}\right) 0 \quad \text { if } b_{n} \leq b_{\Delta}<b_{s} \text { and } \\
& \left(b_{\Delta}-c_{\Delta}\right) \theta_{s}+\theta_{n}-k \quad \text { if } b_{n} \leq b_{\Delta}<b_{s} \text { and } \\
& \left(k<\theta_{s}+\theta_{n} \leq k+k_{\Delta}, \theta_{s} \in(0, T)\right) \\
& \left(b_{s}-c_{\Delta}\right) \max \left\{0, \min \left\{\theta_{n}+T-k, k_{\Delta}\right\}\right\} \quad \text { if } b_{n} \leq b_{\Delta}<b_{s} \text { and } \\
& \left(k+k_{\Delta}<\theta_{s}+\theta_{n} \text { or } T<\theta_{s}\right) \\
& \left(b_{s}-c_{\Delta}\right) 0 \quad \text { if } b_{s}<b_{\Delta} \leq b_{n} \text { and } \\
& \left(b_{\Delta}-c_{\Delta}\right) \min \left\{\theta_{n}-T, \theta_{s}+\theta_{n}-k\right\} \quad \text { if } b_{s}<b_{\Delta}<b_{n} \text { and } \\
& \left(T<\theta_{n} \leq T+k_{\Delta} \text { or } k<\theta_{s}+\theta_{n} \leq k+k_{\Delta}\right) \\
& \left(b_{n}-c_{\Delta}\right) k_{\Delta} \quad \text { if } b_{s}<b_{\Delta} \leq b_{n} \text { and } \\
& \left(T+k_{\Delta}<\theta_{n} \text { or } k+k_{\Delta}<\theta_{s}+\theta_{n}\right) \\
& \left(\left(b_{n} \text { or } b_{s}\right)-c_{\Delta}\right) 0 \quad \text { if } b_{s}=\max \left\{b_{s}, b_{n}, b_{\Delta}\right\} \text { and } \\
& \left(\theta_{n} \leq k+T \text { and } \theta_{s}+\theta_{n} \leq 2 k\right) \\
& \left(b_{\Delta}-c_{\Delta}\right) \min \left\{\theta_{n}-T-k, \theta_{s}+\theta_{n}-2 k\right\} \quad \text { if } b_{s}=\max \left\{b_{s}, b_{n}, b_{\Delta}\right\} \text { and } \\
& \left(k+T<\theta_{s}+\theta_{n} \text { or } 2 k<\theta_{s}+\theta_{n}\right)
\end{aligned}
$$

I explain the payoff function in detail. If $b_{\Delta}=\min \left\{b_{s}, b_{n}, b_{\Delta}\right\}$ and $\left(\theta_{s}+\theta_{n} \leq k_{\Delta}\right)$, supplier $\Delta$ submits the lower bid in the auction, the transmission line is not congested, and it has enough capacity to satisfy total demand; therefore, supplier $\Delta$ sets the price and satisfies total demand. When $b_{\Delta}=\min \left\{b_{s}, b_{n}, b_{\Delta}\right\}$ and $\left(\theta_{s}+\theta_{n}>k_{\Delta}\right)$, supplier $\Delta$ submits the lower bid in the auction, it does not have enough capacity to satisfy total demand; therefore, suppliers $s$ or $n$ are called into operation, set the price, and supplier $\Delta$ sells its production capacity at the price set by any of the other suppliers (left-hand upper panel, figure 5).

If $b_{n} \leq b_{\Delta}<b_{s}$ and $\left(\theta_{s}+\theta_{n} \leq k\right.$ and $\left.\theta_{s} \leq T\right)$, supplier $n$ 's bid is lower than supplier $\Delta$ 's bid, supplier $n$ has enough capacity to satisfy the demand and the transmission line is not congested; therefore, supplier $n$ sets the price, and supplier $\Delta$ 's residual demand is zero. If $b_{n} \leq b_{\Delta}<b_{s}$ and $\left(k<\theta_{s}+\theta_{n} \leq k+k_{\Delta}, \theta_{s} \in(0, T)\right)$, supplier $n$ does not have enough capacity to satisfy the demand and the transmission line is not congested; therefore, supplier $\Delta$ faces a positive residual demand, sets the price and satisfies the demand that cannot be satisfied by supplier $n$. If $b_{n} \leq b_{\Delta}<b_{s}$ and $\left(k+k_{\Delta}<\theta_{s}+\theta_{n}\right.$ or $T<\theta_{s}$ ), suppliers $n$ and $\Delta$ do not have enough capacity to satisfy the demand, or the transmission line is congested; therefore, supplier $s$ sets the price, and supplier $\Delta$ satisfies the demand that cannot be satisfied by suppliers $s$ and $n$ at the price set by supplier $s$ 
(right-hand upper panel, figure 5).

If $b_{s}<b_{\Delta} \leq b_{n}$ and $\left(\theta_{n} \leq T\right.$ and $\left.\theta_{s}+\theta_{n} \leq k\right)$, supplier $s$ 's bid is lower than supplier $\Delta$ 's bid, supplier $s$ has enough capacity to satisfy the demand and the transmission line is not congested; therefore, supplier $s$ sets the price and supplier $\Delta$ 's residual demand is zero. If $b_{s}<b_{\Delta}<b_{n}$ and $\left(T<\theta_{n} \leq T+k_{\Delta}\right.$ or $\left.k<\theta_{s}+\theta_{n} \leq k+k_{\Delta}\right)$, supplier $s$ does not have enough capacity to satisfy the demand or the transmission line is not congested; therefore, supplier $\Delta$ faces a positive residual demand, sets the price and satisfies the demand that cannot be satisfied by supplier $s$. If $b_{s} \leq b_{\Delta} \leq b_{n}$ and $\left(T+k_{\Delta}<\theta_{n}\right.$ or $\left.k+k_{\Delta}<\theta_{s}+\theta_{n}\right)$, suppliers $s$ and $\Delta$ cannot satisfy the demand; therefore, supplier $n$ faces a positive residual demand, sets the price, and supplier $\Delta$ sells its production capacity at the price set by supplier $n$ (left-hand bottom panel, figure 5).

If $b_{\Delta}=\max \left\{b_{s}, b_{n}, b_{\Delta}\right\}$ and $\left(\theta_{n} \leq k+T\right.$ and $\left.\theta_{s}+\theta_{n} \leq 2 k\right)$, supplier $\Delta$ submits the higher bid in the auction, and suppliers $s$ and $n$ have enough capacity to satisfy total demand; therefore, suppliers $s$ or $n$ set the price and supplier $\Delta$ 's residual demand is zero. When $b_{s}=\max \left\{b_{s}, b_{n}, b_{\Delta}\right\}$ and $\left(k+T<\theta_{s}+\theta_{n}\right.$ or $\left.2 k<\theta_{s}+\theta_{n}\right)$, supplier $\Delta$ submits the higher bid in the auction, and suppliers $s$ and $n$ do not have enough capacity to satisfy total demand; therefore, supplier $\Delta$ is called into operation, sets the price and satisfies the residual demand (right-hand bottom panel, figure 5).

In the perfect competition case. The suppliers submit a bid equal to their marginal cost. The efficient supplier (supplier $n$ ) is dispatched first, and its output is denoted by $q_{n}\left(b ; \theta, T, k, k_{\Delta}\right)=\min \left\{\theta_{s}+\theta_{n}, \theta_{n}+T, k\right\}$. Supplier $\Delta$ is dispatched second, and its output is denoted by $q_{\Delta}\left(b ; \theta, T, k, k_{\Delta}\right)=\max \left\{0, \min \left\{\theta_{s}+\theta_{n}-k, \theta_{n}+T-k, k_{\Delta}\right\}\right\}$. The inefficient supplier is dispatched last, and its output is denoted by $q_{s}\left(b ; \theta, k, T, k_{\Delta}\right)=$ $\max \left\{0, \theta_{s}-T, \theta_{s}+\theta_{n}-k-k_{\Delta}\right\}$. Suppliers' profits are equal to:

$$
\pi_{n}\left(b ; \theta, k, T, T_{\Delta}\right)= \begin{cases}b_{n}\left(\theta_{s}+\theta_{n}+T_{\Delta}\right) & \text { if } \theta_{s} \leq T, \text { and } \theta_{s}+\theta_{n} \leq k-T_{\Delta} \\ \left(b_{s} \text { or } P_{\Delta}^{*}\right) \min \left\{\theta_{n}+T+T_{\Delta}, k\right\} & \text { otherwise }\end{cases}
$$

$\pi_{\Delta}\left(b ; \theta, k, T, T_{\Delta}\right)= \begin{cases}b_{n}(0) & \text { if } \theta_{s} \leq T, \text { and } \theta_{s}+\theta_{n} \leq k-T_{\Delta} \\ b_{\Delta}\left(\theta_{s}+\theta_{n}-k\right) & \text { if } \theta_{s} \leq T, \text { and } k+T_{\Delta} \geq \theta_{s}+\theta_{n}>k-T_{\Delta} \\ b_{s} \min \left\{\theta_{n}+T-k, k_{\Delta}\right\} & \text { otherwise }\end{cases}$

$$
\pi_{s}\left(b ; \theta, k, T, T_{\Delta}\right)= \begin{cases}b_{s} \max \left\{\theta_{s}-T, \theta_{s}+\theta_{n}-k-T_{\Delta}\right\} & \text { if } \theta_{s}>T, \text { or } \theta_{s}+\theta_{n}>k+T_{\Delta} \\ \left(b_{n} \text { or } P_{\Delta}^{*}\right)(0) & \text { otherwise }\end{cases}
$$

Given that supplier $n$ submits the lower bid, it is dispatched first and sets the price when it has enough production capacity to satisfy the demand, and when the transmission line that connects nodes North and South is not congested. Otherwise, suppliers $s$, or $\Delta$ are called into operation setting the price, and satisfying the residual demand. 
Figure 6: Inter TSO investment model. Equilibrium
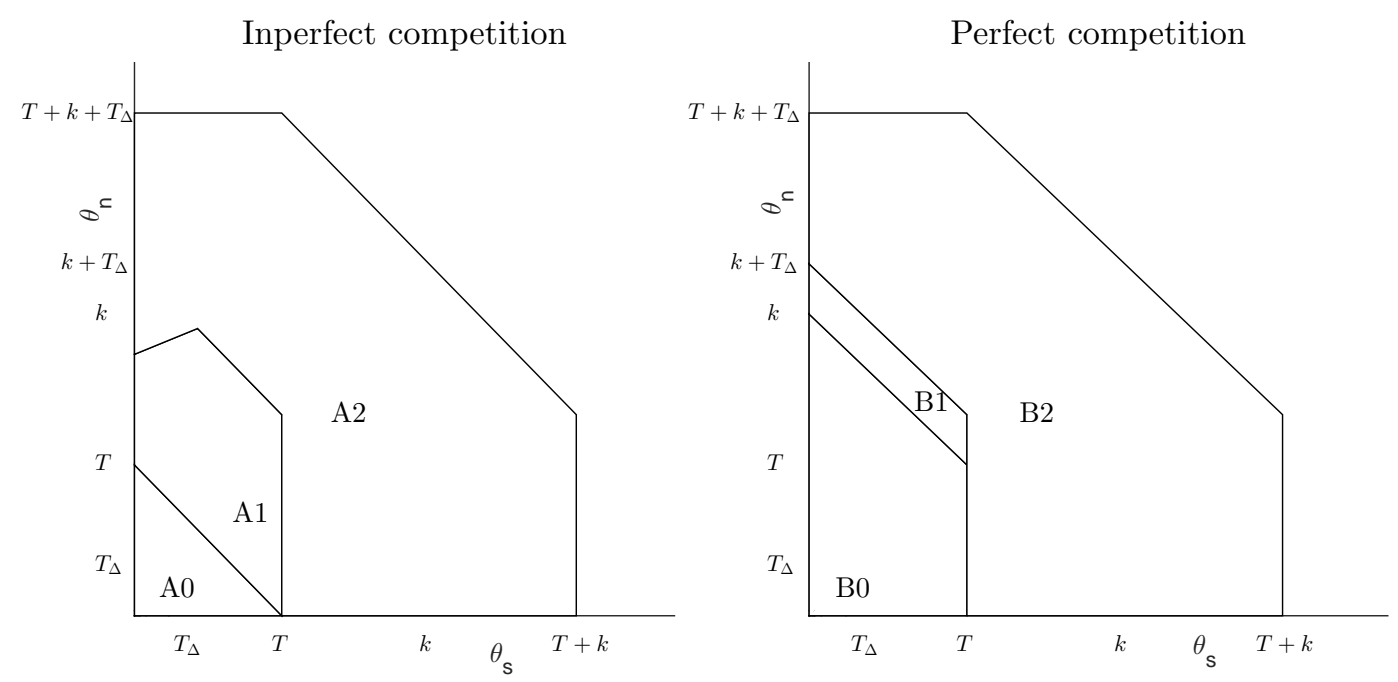

\section{Equilibrium}

\subsection{Inter TSO investment model}

I characterize the equilibrium in a zonal pricing electricity market with two nodes connected by a transmission line with capacity $T$, where one supplier with capacity $(k \mid k>T)$ and production costs 0 is located in node North, one supplier with capacity $k$ and production costs $(c \mid c>0)$ is located in node South, and where node North is connected to an outside perfect competitive zone with equilibrium price $\left(P_{\Delta}^{*} \mid P_{\Delta}^{*}<c\right)$ by a transmission line with capacity $T_{\Delta}$.

First, I characterize the equilibrium when the competition is imperfect.

Lemma 1. When the equilibrium is in pure strategies, the equilibrium price is $P_{\Delta}^{*}, c$ or $P$.

Proof. An equilibrium price $P^{*} \in\left[0, P_{\Delta}^{*}\right)$ does not exist, the efficient supplier raises its bid to $P_{\Delta}^{*}$, and it satisfies the demand in nodes North, South, and in zone Delta for a higher bid. An equilibrium price $P^{*} \in\left(P_{\Delta}^{*}, c\right)$ does not exist, the efficient supplier raises its bid to $c$, and it satisfies the residual demand after supplier $\Delta$ is dispatched. An equilibrium price $P^{*} \in(c, P)$ does not exist, the supplier that is dispatched last raises its bid to $P$, and it satisfies the residual demand for the higher price allowed by the auctioneer

Using this ancillary result, I characterize the equilibrium.

Proposition 1. Inter TSO investment model (imperfect competition). The characterization of the equilibrium falls into one of the next three categories (left-hand panel, figure 6).

i. Low-demand (area $A 0)$. The equilibrium price is $P_{\Delta}^{*}$.

ii. Intermediate demand ( $\operatorname{area} A 1$ ). The equilibrium price is $c$.

iii High-demand (area $A 2$ ). The equilibrium price is $P$. 
When demand is low, suppliers $s$ and $\Delta$ have enough production capacity to satisfy total demand, and neither the transmission line that connects nodes North and South, nor the transmission line that connects node North with zone Delta are congested. Therefore, the suppliers compete fiercely to be dispatched first in the auction, and the efficient supplier submits a bid equal to $P_{\Delta}^{*}$, extracting the efficiency rents and satisfying the demand in nodes North, South, and in zone Delta. When demand is intermediate, the efficient supplier faces a positive residual demand when it is dispatched after supplier $\Delta$; and if that residual demand is high enough, it finds profitable to raise its bid, but still undercutting supplier $s$, satisfying the demand that supplier $\Delta$ cannot satisfy. When demand is high, at least one supplier finds profitable to submit the maximum bid allowed by the auctioneer and satisfy the residual demand.

I characterize the equilibrium in the perfect competition case.

Proposition 2. Inter TSO investment model (perfect competition). The characterization of the equilibrium falls into one of the next three categories (right-hand panel, figure 6).

i. Low-demand (area B0). The equilibrium price is 0 .

ii. Intermediate demand (area $B 1$ ). The equilibrium price is $P_{\Delta}^{*}$.

iii. High-demand (area B2). The equilibrium price is $c$.

In the perfect competition case, the suppliers submit bids equal to their marginal costs. When the demand is low, the efficient supplier has enough production capacity to satisfy total demand, and neither the transmission line that connects nodes North and South, nor the transmission line that connects node North with zone Delta are congested. Therefore, the efficient supplier satisfies the demand in nodes North, South, and in zone Delta, and the equilibrium price is 0 . When the demand is intermediate, the efficient supplier does not have enough production capacity to satisfy total demand, and the transmission line that connects node North with zone Delta is not congested. Therefore, supplier $\Delta$ is called into operation, and the equilibrium price is $P_{\Delta}^{*}$. When the demand is high, the efficient supplier and supplier $\Delta$ do not have enough production capacity to satisfy total demand, or the transmission line that connects nodes North and South is congested. Therefore, the inefficient supplier is called into operation, and the equilibrium price is $c$.

\subsection{Production capacity investment model}

I characterize the equilibrium in a zonal pricing electricity market with two nodes connected by a transmission line with capacity $T$, where one supplier with capacity $(k \mid k>T)$ and production costs 0 , and one supplier with capacity $\left(k_{\Delta} \mid k_{\Delta}=T_{\Delta}\right)$ and production $\operatorname{costs}\left(c_{\Delta} \mid c_{\Delta}<c\right)$ are located in node North, and one supplier with capacity $k$ and production costs $c$ is located in node South.

In the production capacity model, suppliers $s, n$, and $\Delta$ submit their bids in the zone that includes nodes North and South. This is in contrast to the inter TSO investment model, where supplier $\Delta$ does not participate in the zone that includes nodes North and South. i.e, the equilibrium price in the perfect competitive zone Delta is taken as a parameter by suppliers $n$ and $\Delta$. 
Figure 7: Production capacity investment model. Equilibrium

Imperfect competition

Perfect competition
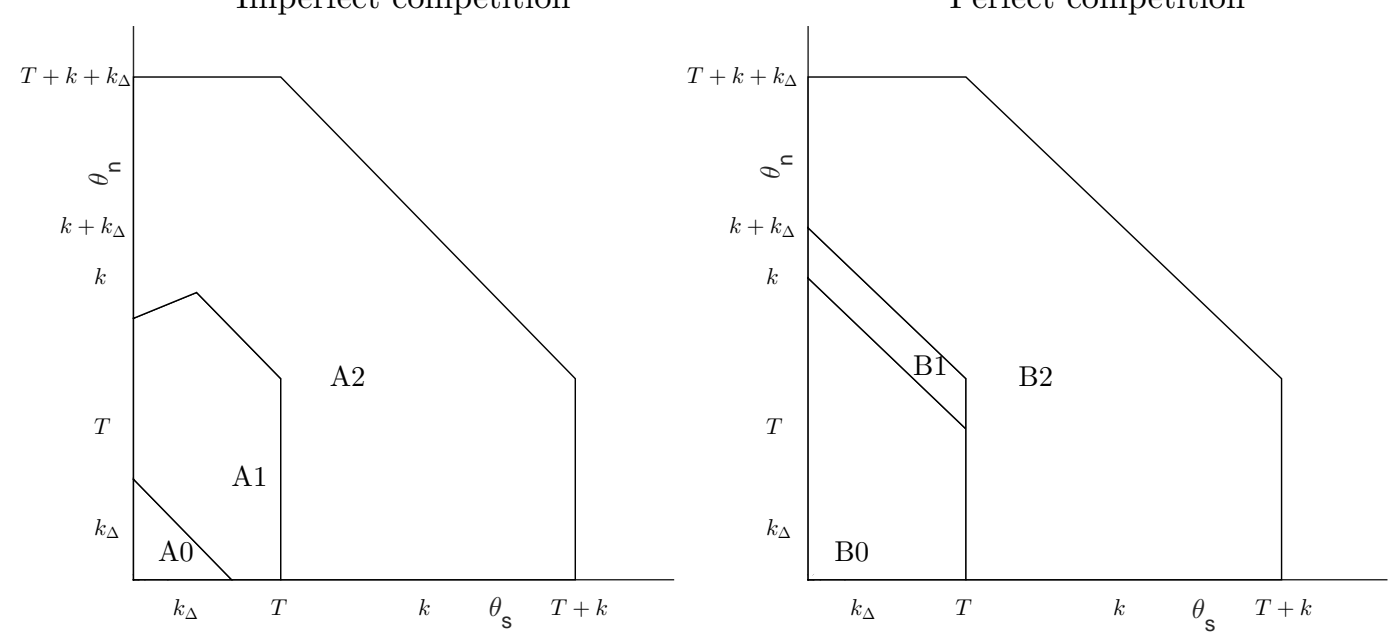

First, I characterize the equilibrium when the competition is imperfect.

Proposition 3. Production capacity investment model (imperfect competition). The characterization of the equilibrium falls into one of the next three categories (left-hand bottom panel, figure 7).

i. Low-demand (area $A 0$ ). The equilibrium price is $P_{\Delta}^{*}$.

ii. Intermediate demand ( $\operatorname{area} A 1$ ). The equilibrium price is $c$.

iii. High-demand (area $A 2$ ). The equilibrium price is $P$.

When demand is low, suppliers $s$ and $\Delta$ have enough production capacity to satisfy total demand, and the transmission line that connects nodes North and South is not congested. Therefore, the suppliers compete fiercely to be dispatched first in the auction, and the efficient supplier submits a bid equal to $P_{\Delta}^{*}$, extracting the efficiency rents and satisfying the demand in nodes North and South. When demand is intermediate, the efficient supplier faces a positive residual demand when it is dispatched after supplier $\Delta$; and if that residual demand is high enough, it finds profitable to raise its bid, but still undercutting supplier $s$, satisfying the demand that supplier $\Delta$ cannot satisfy. When demand is high, at least one supplier finds profitable to submit the maximum bid allowed by the auctioneer and satisfy the residual demand.

I characterize the equilibrium in the perfect competition case.

Proposition 4. Production capacity investment model (perfect competition). The characterization of the equilibrium falls into one of the next three categories (right-hand panel, figure 6).

i. Low-demand (area B0). The equilibrium price is 0 .

ii. Intermediate demand (area $B 1$ ). The equilibrium price is $P_{\Delta}^{*}$.

iii. High-demand (area B2). The equilibrium price is $c$. 
The equilibrium is exactly as in the inter TSO investment model.

When the competition is perfect, the equilibrium outcome is the same for both models. In contrast, when the competition is imperfect, the equilibrium outcome is different depending on the model. Proposition five summarizes those differences.

Proposition 5. Model comparison (imperfect competition).

i. In the inter TSO investment model, the equilibrium prices are lower than in the production capacity investment model.

ii. In the inter TSO investment model, suppliers' profits are larger than in the production capacity investment model only when the demand is low.

The inter TSO investment model outperforms the production capacity investment model by maximizing consumers welfare because of two different effects: the "size effect," and the "competition effect."

To explain the size and the competition effects. I proceed in two steps. First, to explain the "size effect," I assume that the supplier that enter in node North in the production capacity investment model behaves competitively, i.e., it behaves as the supplier located in the outside zone in the inter TSO investment model. Therefore, I can isolate the impact that an increase in transmission capacity has on equilibrium prices. In the inter TSO investment model, the total demand is larger than in the production capacity investment model since it comprises the demand in nodes North, South, and in addition, it also includes the demand in the zone Delta. When the size of the market is large, the efficient supplier finds more profitable to satisfy the total demand, and extract the efficiency rents by submitting a low bid. Therefore, due to the size effect, the equilibrium prices in the inter TSO investment model are lower or equal than in the production capacity investment model. Graphically, the size effect increases area $A 0$, that in the inter TSO investment model is larger or equal than in the production capacity investment model (figures 6 and 7 respectively).

Second, to explain the "competition effect," I assume that the supplier that enter in node North in the production capacity investment model behaves strategically by submitting its own bid that is higher or equal than its marginal costs. If the investment in production capacity is high enough, the supplier that invests in production capacity faces a high residual demand, and it can find profitable to submit the maximum bid allowed by the auctioneer inducing an increase in the equilibrium prices. Therefore, due to the competition effect, the equilibrium prices in the inter TSO investment model are lower or equal than in the production capacity investment model. Graphically, the competition effect increases area $A 1$, that in the inter TSO investment model is larger or equal than in the production capacity investment model (figures 6 and 7 respectively).

Therefore, using proposition five, we can disentangle if the reduction in equilibrium prices in the inter TSO investment model is due to an increase in the size of the market, or is due to an increase in competition.

The inter TSO investment model outperforms the capacity investment model by maximizing suppliers' profits only when the demand is low. When the demand is low, the 
efficient supplier submits the lower bid, and the equilibrium prices are low in both models. However, in the inter TSO investment model, the size of the market is larger, and so they are suppliers' profits. When the demand is high, the equilibrium price in nodes North and South is higher than in the outside zone, and the electricity flows from the outside zone to node North. Therefore, the size of the market is the same in both models. However, due to the competition effect, the equilibrium prices in the capacity investment model are equal or higher than in the inter TSO investment model, and so they are suppliers' profits.

These results contrast with the comparison between the inter TSO investment model the production capacity investment model and the intra TSO investment model in annex two, where a rank between models in terms of consumers welfare and suppliers' profits cannot be established.

\section{Conclusion}

A successful transformation to a carbon neutral energy system requires the correct investments in transmission and production capacity. The European Network of Transmission System Operators for Electricity identifies four types of investments necessary to promote proper functioning of electricity markets: Investments in transmission capacity between zones (inter TSO investments); investments in transmission capacity within the same zone (intra TSO investments); investments in transmission capacity to connect isolated renewable production capacity with the electricity grid; and production capacity investments (ENTSO-E, 2014). In this paper, I have analyzed the effect that inter TSO investments, intra TSO investments, and production capacity investments have on consumer welfare.

In the specific setting of this paper, when the competition is perfect, I show that inter TSO investments and production capacity investments have the same effects on consumers welfare and suppliers' profits. In contrast, when the competition is imperfect, consumers welfare and suppliers' profits are different depending on the type of investment.

When the comptition is imperfect, the inter TSO investment model outperforms the production capacity investment model by maximizing consumers welfare because of the "size effect" and the "competition effect," where the "size effect" captures the impact that the difference in the demand size has on equilibrium prices, and the "competition effect" captures the impact that the difference in competition has on equilibrium prices. When the demand is low, the equilibrium price is low in both models, but in the inter TSO investment model, the demand is larger, and so they are suppliers' profits. In contrast, when the demand is high, the demand is the same in both models, but in the production capacity investment model, due to the "competition effect," the equilibrium price is higher, and so they are suppliers' profits.

In annex two, I characterize the equilibrium in the intra TSO investment model, and I compare that model with the inter TSO investment and the production capacity investment models. In the comparisons between the intra TSO investment model and the other two models, it is not possible to establish a clear rank in terms of consumers welfare and suppliers' profits.

In the specific setting of this paper, I characterize the equilibrium, and I provide a 
clear description of the economic forces that drive the results. In the next future, based on this analysis, I would like to extend the model to generalize the results.

As in Bjørndal and Jørnsten (2001), I work out the equilibrium, taking into account the transmission constraints, and I do not consider the possible effects of redispatching on equilibrium outcome allocations. However, as has been proved by Stoft (1998), or Dijk and Willems (2011), in a zonal pricing electricity market, redispatching could have important implications for equilibrium outcome allocations. When the TSO introduces redispatch to work out the equilibrium in a zonal pricing electricity market, suppliers' profits do not only depend on suppliers' dispatch, but also on suppliers' differences in bids. This change in suppliers' profit functions affects the way in which the equilibrium bids are worked out in a uniform price auction. In the near future, I will characterize the equilibrium when a market-based redispatch mechanism is introduced in the auction. 


\section{Annex 1. Inter TSO and production capacity investment models}

\section{Inter TSO investment model}

Proposition 1. By lemma one, the equilibrium price could be $P_{\Delta}^{*}$, c, or $P$; where $\left(P_{\Delta}^{*}<c<P\right)$.

When demand is low, suppliers $s$ and $\Delta$ have enough production capacity to satisfy total demand, and neither the transmission line that connects nodes North and South, nor the transmission line that connects node North with zone Delta are congested. Therefore, the suppliers compete fiercely to be dispatched first in the auction, and the efficient supplier submits a bid equal to $P_{\Delta}^{*}$, extracting the efficiency rents and satisfying the demand in nodes North, South, and in zone Delta. When demand is intermediate, the efficient supplier faces a positive residual demand when it is dispatched after supplier $\Delta$; and if that residual demand is high enough, it finds profitable to raise its bid, but still undercutting supplier $s$, satisfying the demand that supplier $\Delta$ cannot satisfy. When demand is high, at least one supplier finds profitable to submit the maximum bid allowed by the auctioneer and satisfy the residual demand.

Therefore, to characterize the equilibrium, it is necessary to work out the demand values $\left(\theta_{s}, \theta_{n}\right)$ for which each supplier prefers to set a price equal to $P_{\Delta}^{*}, c$, or $P$.

First, the efficient supplier (supplier $n$ ) prefers to submit the lower bid and satisfy total demand when:

$$
c\left(\theta_{s}+\theta_{n}-T_{\Delta}\right)<P_{\Delta}^{*} \min \left\{\theta_{s}+\theta_{n}+T_{\Delta}, k\right\}
$$

Doing some algebra

$$
\begin{aligned}
\left(c-P_{\Delta}^{*}\right)\left(\theta_{s}+\theta_{n}\right)<\left(c+P_{\Delta}^{*}\right) T_{\Delta} \Leftrightarrow \theta_{n} & <\frac{c+P_{\Delta}^{*}}{c-P_{\Delta}^{*}} T_{\Delta}-\theta_{s}, \theta_{s}+\theta_{n}+T_{\Delta} \leq k \\
c\left(\theta_{s}+\theta_{n}-T_{\Delta}\right)<P_{\Delta}^{*} k \Leftrightarrow \theta_{n} & <\frac{P_{\Delta}^{*} k}{c}+T_{\Delta}-\theta_{s}, \theta_{s}+\theta_{n}+T_{\Delta}>k
\end{aligned}
$$

The efficient supplier prefers to undercut the inefficient supplier and satisfy the demand that cannot be satisfied by supplier $\Delta$ when:

$$
\begin{aligned}
P \max \left\{0, \theta_{n}-T-T_{\Delta}, \theta_{s}+\theta_{n}-k-T_{\Delta}\right\} & <c \min \left\{\theta_{s}+\theta_{n}-T_{\Delta}, \theta_{n}+T-T_{\Delta}, k\right\} \Leftrightarrow \\
P\left(\theta_{n}-T-T_{\Delta}\right) & <c \min \left\{\theta_{s}+\theta_{n}-T_{\Delta}, k\right\}, \theta_{s} \leq T \\
P\left(\theta_{s}+\theta_{n}-k-T_{\Delta}\right) & <c \min \left\{\theta_{n}+T-T_{\Delta}, k\right\}, \theta_{s}>T
\end{aligned}
$$

Doing some algebra, 


$$
\begin{array}{r}
\theta_{n}(P-c)<P T+(P-c) T_{\Delta}+c \theta_{s}, \theta_{s} \leq T, \text { and } \theta_{s}+\theta_{n}+T_{\Delta} \leq k \Leftrightarrow \\
\theta_{n}<\frac{P T+(P-c) T_{\Delta}}{P-c}+\frac{c \theta_{s}}{P-c}, \theta_{s} \leq T, \text { and } \theta_{s}+\theta_{n}+T_{\Delta} \leq k \\
P\left(\theta_{n}-T-T_{\Delta}\right)<c k, \theta_{s} \leq T \text { and } \theta_{s}+\theta_{n}+T_{\Delta}>k \Leftrightarrow \\
\theta_{n}<T+T_{\Delta}+\frac{c k}{P}, \theta_{s} \leq T \text { and } \theta_{s}+\theta_{n}+T_{\Delta}>k
\end{array} \quad \Leftrightarrow \quad \Leftrightarrow
$$

Second, the inefficient supplier (supplier $s$ ) prefers to submit a low bid and satisfy total demand when:

$(P-c) \max \left\{0, \theta_{s}-T, \theta_{s}+\theta_{n}-k-T_{\Delta}\right\}<(c-c) \min \left\{\theta_{s}+\theta_{n}-T_{\Delta}, \theta_{s}+T-T_{\Delta}, k\right\} \Leftrightarrow$

Doing some algebra,

$$
\begin{array}{r}
(P-c)\left(\theta_{s}+\theta_{n}-k-T_{\Delta}\right)<(c-c) \min \left\{\theta_{s}+\theta_{n}-T_{\Delta}, \theta_{s}+T-T_{\Delta}, k\right\}, \theta_{s} \leq T \Leftrightarrow \\
\theta_{n}<k+T_{\Delta}-\theta_{s}, \theta_{s} \leq T \\
(P-c)\left(\theta_{s}-T\right)<(c-c) \min \left\{\theta_{s}+\theta_{n}-T_{\Delta}, \theta_{s}+T-T_{\Delta}, k\right\}, \theta_{s}>T .
\end{array}
$$

The inequality never holds when $\theta_{s}>T$.

Finally, I work out the combination of demands $\left(\theta_{s}, \theta_{n}\right)$ that defines the low, intermediate and high demand areas. Equation 1 defines the low-demand equilibrium area (area $A 0$, left-hand panel in figure 6). The intersection of the areas defined by equations 2 and 3 defines the intermediate demand equilibrium (area $A 1$, left-hand panel in figure 6). Any combination of demands $\left(\theta_{s}, \theta_{n}\right)$ larger that those in area $A 1$ defines the high-demand equilibrium area (area $A 2$, left-hand panel in figure 6).

In the low-demand area, the equilibrium is $\left(b_{s}^{*}=c, b_{n}^{*}=P_{\Delta}^{*}, b_{\Delta}^{*}=P_{\Delta}^{*}\right)$. In the intermediate demand, the equilibrium is $\left(b_{s}^{*}=b_{n}^{*}=c, b_{\Delta}^{*}=P_{\Delta}^{*}\right)$. In the high-demand area, the equilibrium is 8

$$
\begin{gathered}
\left(b_{s}^{*}=P, b_{n}^{*} \in\left[0, c+\frac{(P-c) \max \left\{\theta_{s}-T, \theta_{s}+\theta_{n}-k-T_{\Delta}\right\}}{\min \left\{\theta_{s}+\theta_{n}-T_{\Delta}, \theta_{s}+T-T_{\Delta}, k\right\}}\right], b_{\Delta}^{*}=P_{\Delta}^{*}\right), \text { or } \\
\left(b_{s}^{*} \in\left[0, \frac{P \max \left\{\theta_{n}-T-T_{\Delta}, \theta_{s}+\theta_{n}-k-T_{\Delta}\right\}}{\min \left\{\theta_{s}+\theta_{n}-T_{\Delta}, \theta_{n}+T-T_{\Delta}, k\right\}}\right], b_{n}^{*}=P, b_{\Delta}^{*}=P_{\Delta}^{*}\right) .
\end{gathered}
$$

\footnotetext{
${ }^{8}$ In the inter TSO investment model, supplier $\Delta$ does not participate in the auction. Therefore, it is not necessary to take into account its bid to characterize the equilibrium, or to work out its profit. However, I characterize the equilibrium taken into account supplier $\Delta$ 's bid, and I work out its profit to compare these results with those in the production capacity investment model.
} 
In the low-demand area (area $A 0$ ), suppliers' profits are $\pi_{s}^{*}=0, \pi_{n}^{*}=P_{\Delta}^{*} \min \left\{\theta_{s}+\theta_{n}+T_{\Delta}, k\right\}$, and $\pi_{\Delta}^{*}=0$. In the intermediate demand area (area $A 1$ ), suppliers' profits are $\pi_{s}^{*}=0, \pi_{n}^{*}=$ $c\left(\theta_{s}+\theta_{n}-T_{\Delta}\right)$, and $\pi_{\Delta}^{*}=\left(c-P_{\Delta}^{*}\right) T_{\Delta}$. In the high-demand area (area $\left.A 2\right)$, depending on the equilibrium (equation 4), suppliers' profits are $\pi_{s}^{*}=(P-c) \max \left\{\theta_{s}-T, \theta_{s}+\theta_{n}-k-T_{\Delta}\right\}$, $\pi_{n}^{*}=P \min \left\{\theta_{n}+T-T_{\Delta}, k\right\}$, and $\pi_{\Delta}^{*}=\left(P-P_{\Delta}^{*}\right) T_{\Delta} ;$ or $\pi_{s}^{*}=(P-c) \min \left\{\theta_{s}+T-T_{\Delta}, k\right\}$, $\pi_{n}^{*}=P \max \left\{\theta_{n}-T-T_{\Delta}, \theta_{s}+\theta_{n}-k-T_{\Delta}\right\}$, and $\pi_{\Delta}^{*}=\left(P-P_{\Delta}^{*}\right) T_{\Delta}$.

Proposition 2. In the perfect competition case, the suppliers submit bids equal to their marginal costs. When the demand is low, the efficient supplier has enough production capacity to satisfy the demand in nodes North and South, and the transmission line that connects nodes North and South is not congested. Therefore, the efficient supplier satisfies the demand in nodes North, South, and in zone Delta (up to its production capacity), and the equilibrium price is 0 . Therefore, the low-demand area (area $B 0$, right-hand panel in figure 60 is defined by $\theta_{n} \leq k-\theta_{s}, \theta_{s} \in[0, T]$. Suppliers' profits are $\pi_{s}^{*}=0, \pi_{n}^{*}=0, \pi_{\Delta}^{*}=0$

When the demand is intermediate, the efficient supplier does not have enough production capacity to satisfy total demand, and the transmission line that connects node North with zone Delta is not congested, supplier $\Delta$ is called into operation, and the equilibrium price is $P_{\Delta}^{*}$. Therefore, the intermediate demand area (area $B 1$, right-hand panel in figure 6] is defined by $k-\theta_{s}<\theta_{n} \leq k+T_{\Delta}-\theta_{s}, \theta_{s} \in[0, T]$. Suppliers' profits are $\pi_{s}^{*}=0$, $\pi_{n}^{*}=P_{\Delta}^{*} k, \pi_{\Delta}^{*}=0$

When the demand is high, the efficient supplier and supplier $\Delta$ do not have enough production capacity to satisfy total demand, or the transmission line that connects nodes North and South is congested, the inefficient supplier is called into operation, and the equilibrium price is $c$. Therefore, the high-demand area (area $B 2$, right-hand panel in figure 60) is defined by $k+T_{\Delta}-\theta_{s}<\theta_{n}, \theta_{s} \in[0, T] ; \theta_{n}>0, \theta_{s} \in(T, T+k]$. Suppliers' profits are $\pi_{s}^{*}=0, \pi_{n}^{*}=c \max \left\{\theta_{n}+T, k\right\}, \pi_{\Delta}^{*}=c \max \left\{0, T_{\Delta}\right\}$

\section{Production capacity investment model}

Proposition 3. By lemma one, the equilibrium price could be $c_{\Delta}$, $c$, or $P$; where $\left(c_{\Delta}<c<P\right)$.

When demand is low, suppliers $s$ and $\Delta$ have enough production capacity to satisfy total demand, and the transmission line that connects nodes North and South is not congested. Therefore, the suppliers compete fiercely to be dispatched first in the auction, and the efficient supplier submits a bid equal to $P_{\Delta}^{*}$, extracting the efficiency rents and satisfying the demand in nodes North and South. When demand is intermediate, the efficient supplier faces a positive residual demand when it is dispatched after supplier $\Delta$; and if that residual demand is high enough, it finds profitable to raise its bid, but still undercutting supplier $s$, satisfying the demand that supplier $\Delta$ cannot satisfy. When demand is high, at least one supplier finds profitable to submit the maximum bid allowed by the auctioneer and satisfy the residual demand.

Therefore, to characterize the equilibrium, it is necessary to work out the demand values $\left(\theta_{s}, \theta_{n}\right)$ for which each supplier prefers to set a price equal to $c_{\Delta}$, $c$, or $P$. 
First, the efficient supplier ( $\operatorname{supplier} n$ ) prefers to submit the lower bid and satisfy total demand when:

$$
c\left(\theta_{s}+\theta_{n}-k_{\Delta}\right)<c_{\Delta} \min \left\{\theta_{s}+\theta_{n}, k\right\}
$$

Doing some algebra

$$
\begin{gathered}
\left(c-c_{\Delta}\right)\left(\theta_{s}+\theta_{n}\right)<c k_{\Delta} \Leftrightarrow \theta_{n}<\frac{c}{c-c_{\Delta}} k_{\Delta}-\theta_{s}, \theta_{s}+\theta_{n} \leq k \\
c\left(\theta_{s}+\theta_{n}-k_{\Delta}\right)<c_{\Delta} k \Leftrightarrow \theta_{n}<\frac{c_{\Delta} k}{c}+k_{\Delta}-\theta_{s}, \theta_{s}+\theta_{n}>k
\end{gathered}
$$

The efficient supplier prefers to undercut the inefficient supplier and satisfy the demand that cannot be satisfied by supplier $\Delta$ when:

$$
\begin{aligned}
P \max \left\{\theta_{n}-T-k_{\Delta}, \theta_{s}+\theta_{n}-k_{\Delta}, k\right\} & <c \min \left\{\theta_{s}+\theta_{n}-k_{\Delta}, \theta_{n}+T-k_{\Delta} k\right\} \Leftrightarrow \\
P\left(\theta_{n}-T-k_{\Delta}\right) & <c \min \left\{\theta_{s}+\theta_{n}-k_{\Delta}, k\right\}, \theta_{s} \leq T \\
P\left(\theta_{s}+\theta_{n}-k-k_{\Delta}\right) & <c \min \left\{\theta_{n}+T-k_{\Delta}, k\right\}, \theta_{s}>T
\end{aligned}
$$

Doing some algebra,

$$
\begin{aligned}
(P-c) \theta_{n}<P T+(P-c) k_{\Delta}+c \theta_{s}, \theta_{s} \leq T, \text { and } \theta_{s}+\theta_{n}-k_{\Delta} \leq k & \Leftrightarrow \\
\theta_{n}<\frac{P T+(P-c) k_{\Delta}}{P-c}+\frac{c \theta_{s}}{P-c}, \theta_{s} \leq T, \text { and } \theta_{s}+\theta_{n}-k_{\Delta} \leq k & \\
(P-c)\left(\theta_{n}-T-k_{\Delta}\right)<c k, \theta_{s} \leq T, \text { and } \theta_{s}+\theta_{n}-k_{\Delta}>k & \Leftrightarrow \\
\theta_{n}<\frac{c k}{P-c}+T+k_{\Delta}, \theta_{s} \leq T, \text { and } \theta_{s}+\theta_{n}-k_{\Delta}>k & \\
(P-c)\left(\theta_{n}-k_{\Delta}\right)<P k+c T-P \theta_{s}, \theta_{s}>T, \text { and } \theta_{n}+T-k_{\Delta} \leq k & \Leftrightarrow \\
\theta_{n}<\frac{P k+c T-P \theta_{s}}{P-c}+k_{\Delta}, \theta_{s}>T, \text { and } \theta_{n}+T-k_{\Delta} \leq k & \\
P\left(\theta_{s}+\theta_{n}-k-k_{\Delta}\right)<c k, \theta_{s}>T, \text { and } \theta_{n}+T-k_{\Delta}>k & \Leftrightarrow \\
\theta_{n}<k+k_{\Delta}+\frac{c k}{P}-\theta_{s}, \theta_{s}>T, \text { and } \theta_{n}+T-k_{\Delta}>k &
\end{aligned}
$$

Second, supplier $\Delta$ prefers to be dispatched second in the auction when:

$$
\begin{gathered}
\left(c-c_{\Delta}\right)\left(\theta_{s}+\theta_{n}-k\right)>\left(c_{\Delta}-c_{\Delta}\right) \min \left\{\theta_{s}+\theta_{n}, k_{\Delta}\right\}, \theta_{s} \leq T \Leftrightarrow \theta_{n}>k-\theta_{s} \\
\left(c-c_{\Delta}\right)\left(\theta_{n}+T-k\right)>\left(c_{\Delta}-c_{\Delta}\right) \min \left\{\theta_{n}+T, k_{\Delta}\right\}, \theta_{s}>T \Leftrightarrow \theta_{n}>k-T
\end{gathered}
$$

Supplier $\Delta$ prefers to be dispatched last in the auction when:

$$
\begin{aligned}
\left(P-c_{\Delta}\right) \max \left\{0, \theta_{n}-T-k, \theta_{s}+\theta_{n}-2 k\right\} & >\left(c-c_{\Delta}\right) \min \left\{\theta_{s}+\theta_{n}-k, \theta_{n}+T-k, k_{\Delta}\right\} \Leftrightarrow \\
\left(P-c_{\Delta}\right)\left(\theta_{n}-T-k\right) & >\left(c-c_{\Delta}\right) \min \left\{\theta_{s}+\theta_{n}-k, k_{\Delta}\right\}, \theta_{s} \leq T \\
\left(P-c_{\Delta}\right)\left(\theta_{s}+\theta_{n}-2 k\right) & >\left(c-c_{\Delta}\right) \min \left\{\theta_{n}+T-k, k_{\Delta}\right\}, \theta_{s}>T
\end{aligned}
$$

Doing some algebra, 


$$
\begin{aligned}
(P-c)\left(\theta_{n}-k\right)>\left(P-c_{\Delta}\right) T+\left(c-c_{\Delta}\right) \theta_{s}, \theta_{s} \leq T, \text { and } \theta_{s}+\theta_{n}-k \leq k_{\Delta} & \Leftrightarrow \\
\theta_{n}>\frac{\left(P-c_{\Delta}\right) T+\left(c-c_{\Delta}\right) \theta_{s}}{P-c}+k, \theta_{s} \leq T, \text { and } \theta_{s}+\theta_{n}-k \leq k_{\Delta} & \\
\left(P-c_{\Delta}\right)\left(\theta_{n}-T-k\right)>\left(c-c_{\Delta}\right) k_{\Delta}, \theta_{s} \leq T, \text { and } \theta_{s}+\theta_{n}-k>k_{\Delta} & \Leftrightarrow \\
\theta_{n}>\frac{\left(c-c_{\Delta}\right) k_{\Delta}}{P-c_{\Delta}}+T+k, \theta_{s} \leq T, \text { and } \theta_{s}+\theta_{n}-k>k_{\Delta} & \Leftrightarrow \\
(P-c) \theta_{n}>\left(c-c_{\Delta}\right)(T-k)+\left(P-c_{\Delta}\right)\left(2 k-\theta_{s}\right), \theta_{s}>T, \text { and } \theta_{n}+T-k \leq k_{\Delta} & \Leftrightarrow \\
\theta_{n}>\frac{\left(c-c_{\Delta}\right)(T-k)+\left(P-c_{\Delta}\right)\left(2 k-\theta_{s}\right)}{P-c}, \theta_{s}>T, \text { and } \theta_{n}+T-k \leq k_{\Delta} & \\
\left(P-c_{\Delta}\right)\left(\theta_{s}+\theta_{n}-2 k\right)>\left(c-c_{\Delta}\right) k, \theta_{s}>T, \text { and } \theta_{n}+T-k>k_{\Delta} & \Leftrightarrow \\
\theta_{n}>\frac{\left(c-c_{\Delta}\right) k}{\left(P-c_{\Delta}\right)}+2 k-\theta_{s}, \theta_{s}>T, \text { and } \theta_{n}+T-k>k_{\Delta} &
\end{aligned}
$$

Third, the inefficient supplier (supplier $s$ ) prefers to submit a low bid and satisfy total demand when:

$$
(P-c) \max \left\{0, \theta_{s}-T, \theta_{s}+\theta_{n}-k-k_{\Delta}\right\}<(c-c) \min \left\{\theta_{s}+\theta_{n}-k_{\Delta}, \theta_{s}+T-k_{\Delta}, k\right\}
$$

Doing some algebra,

$$
\begin{array}{r}
(P-c)\left(\theta_{s}+\theta_{n}-k-k_{\Delta}\right)<(c-c) \min \left\{\theta_{s}+\theta_{n}-k_{\Delta}, \theta_{s}+T-k_{\Delta}, k\right\}, \theta_{s} \leq T \Leftrightarrow \\
\theta_{n}<k+k_{\Delta}-\theta_{n}, \theta_{s} \leq T \\
(P-c)\left(\theta_{s}-T\right)<(c-c) \min \left\{\theta_{s}+\theta_{n}-k_{\Delta}, \theta_{s}+T-k_{\Delta}, k\right\}, \theta_{s}>T . \\
\text { The inequality never holds when } \theta_{s}>T .
\end{array}
$$

Finally, I work out the combination of demands $\left(\theta_{s}, \theta_{n}\right)$ that defines the low, intermediate and high demand areas. Equation 5 defines the low-demand equilibrium area (area $A 0$, left-hand panel in figure 7). The intersection of the areas defined by equations 6 . 7. and 9 defines the intermediate demand equilibrium area (area $A 1$, left-hand panel in figure 7). Any combination of demands $\left(\theta_{s}, \theta_{n}\right)$ larger that those in area $A 1$ defines the high-demand equilibrium area (area $A 2$, left-hand panel in figure 7).

In the low-demand area, the equilibrium is $\left(b_{s}^{*}=c, b_{n}^{*}=c_{\Delta}, b_{\Delta}^{*}=c_{\Delta}\right)$. In the intermediate demand, the equilibrium is

$$
\begin{gathered}
\left(b_{s}^{*}=b_{n}^{*}=c, b_{\Delta}^{*} \in\left[c_{\Delta}, \frac{c \max \left\{\theta_{n}-T-k_{\Delta}, \theta_{s}+\theta_{n}-k_{\Delta}\right\}}{\min \left\{\theta_{s}+\theta_{n}, k_{\Delta}\right\}}\right]\right), \text { or } \\
\left(b_{s}^{*}=b_{\Delta}^{*}=c, b_{n}^{*} \in\left[0, c_{\Delta}+\frac{\left(c-c_{\Delta}\right) \max \left\{\theta_{s}+\theta_{n}-k, \theta_{s}+T-k\right\}}{\min \left\{\theta_{s}+\theta_{n}, k_{\Delta}\right\}}\right]\right) .
\end{gathered}
$$

In the high-demand area, one of the suppliers submits the higher bid allowed by the auctioneer, and the other two submit a bid that makes undercutting unprofitable. 
In the low-demand area (area $A 0$ ), suppliers' profits are $\pi_{s}^{*}=0, \pi_{n}^{*}=c_{\Delta} \min \left\{\theta_{s}+\theta_{n}, k\right\}$, $\pi_{\Delta}^{*}=0$. In the intermediate demand area (area $A 1$ ), depending on the equilibrium (equation 10, suppliers' profits are $\pi_{s}^{*}=0, \pi_{n}^{*}=c\left(\theta_{s}+\theta_{n}-k_{\Delta}\right), \pi_{\Delta}^{*}=\left(c-c_{\Delta}\right) k_{\Delta}$; or $\pi_{s}^{*}=0$, $\pi_{n}^{*}=c k, \pi_{\Delta}^{*}=\left(c-c_{\Delta}\right)\left(\theta_{s}+\theta_{n}-k\right)$. In the high-demand area (area $\left.A 2\right)$ suppliers' profits depend on the equilibrium in which the suppliers coordinate.

Proposition 4. The proof is as in proposition 2.

\section{Proposition 5.}

First, I prove that area $A 0$ in the inter TSO investment model (figure 6) is larger than area $A 0$ in the production capacity investment model (figure 7). It is enough to compare equations 1 and 5 . In the proof, I am using that $T_{\Delta}=k_{\Delta}$, and that $P_{\Delta}^{*}=c_{\Delta}$.

$$
\begin{aligned}
\frac{c+c_{\Delta}}{c-c_{\Delta}} k_{\Delta}-\theta_{s} & \geq \frac{c}{c-c_{\Delta}} k_{\Delta}-\theta_{s}, \theta_{s} \leq T, \text { and } \theta_{s}+\theta_{n} \leq k \\
\frac{c_{\Delta}}{c-c_{\Delta}} k+k_{\Delta}-\theta_{s} & \geq \frac{c_{\Delta}}{c-c_{\Delta}} k+k_{\Delta}-\theta_{s}, \theta_{s} \leq T, \text { and } \theta_{s}+\theta_{n}>k
\end{aligned}
$$

Second, I prove that area $A 1$ in the production capacity investment model (figure 7) can be smaller than area $A 1$ in the inter TSO model (figure 6). I have to compare equations 2 and 8 . There are different possibilities.

First $\left(\theta_{s} \leq T\right.$, and $\left.\theta_{s}+\theta_{n}-k_{\Delta} \leq k\right)$, I have to show that

$$
\begin{array}{r}
\frac{\left(P-c_{\Delta}\right) T+(P-c) k}{P-c}+\frac{\left(c-c_{\Delta}\right) \theta_{s}}{P-c} \leq \frac{P T+(P-c) k_{\Delta}}{P-c}+\frac{c \theta_{s}}{P-c}, \theta_{s} \leq T, \text { and } \\
\theta_{s}+\theta_{n}-k_{\Delta} \leq k
\end{array}
$$

Given that both equations are increasing in $k$ and $k_{\Delta}$, I assume that $k=k_{\Delta}$, and I analyze the relation between the equations when there exist difference on production costs. When $c_{\Delta} \longrightarrow 0$, both equations are equal. When $c_{\Delta} \longrightarrow c$, the inequality holds. The equations are continuous in $k, k_{\Delta}, c$ and $c_{\Delta}$. Therefore, there is a combination of parameters for which the inequality holds, i.e., the equilibrium price is $c$ in the inter TSO model, but $P$ in the production capacity investment model. This result is very intuitive, and it is in line with the literature. If the suppliers are symmetric in production capacities, the inefficient supplier submits higher bids for lower realization of the demands.

Second $\left(\theta_{s} \leq T\right.$, and $\left.\theta_{s}+\theta_{n}-k_{\Delta}>k\right)$, I have to show that

$$
\begin{array}{r}
\frac{\left(c-c_{\Delta}\right) k_{\Delta}}{P-c_{\Delta}}+T+k \leq \frac{c k}{P}+T+k_{\Delta}, \theta_{s} \leq T, \text { and } \\
\theta_{s}+\theta_{n}-k_{\Delta}>k
\end{array}
$$

The proof is as when $\theta_{s} \leq T$, and $\theta_{s}+\theta_{n}-k_{\Delta}>k$

Third, when $\theta_{s}>T$, the proof proceeds in the same way. 
Finally, it easy to show that when the demand is low (area $A 0$ in the production capacity investment model), the profits in the inter TSO investment model are larger than in the production capacity investment model. When the equilibrium price is low, the equilibrium price is the same in both models, but in the inter TSO investment model, the efficient supplier sells its production capacity in nodes North, South and in zone Delta. In contrast, in the investment capacity model, the efficient supplier only sells its production capacity in nodes North and South. Therefore, in the inter TSO investment model, the equilibrium prices are larger than in the production capacity investment model. In the rest of the areas (areas $A 0$ and $A 1$ ), the electricity never flows from node North to zone Delta, and as I have shown previously in this proposition, the equilibrium price in the production capacity investment model is equal or larger than in the inter TSO investment model. Therefore, the equilibrium profits in the inter TSO investment model are equal or lower than in the production capacity model.

\section{Annex 2. Intra TSO investment model}

In the paper, I characterize the equilibrium in the inter TSO and in the production capacity investment models. In this annex, I complete the analysis by characterizing the equilibrium when the TSO invests in transmission capacity between nodes North and South (intra TSO investment model). I also compare the equilibrium in the intra TSO investment model with the equilibrium in the inter TSO investment model and the production capacity investment model.

Set up of the model (figure 8). As in the inter TSO model, there exists a zonal pricing electricity market with two electricity nodes, node North and node South, that are connected by a transmission line with capacity $T$. The suppliers are symmetric in production capacities, and asymmetric in production costs, where the efficient supplier is located in node North, and the inefficient supplier is located in node South. In addition, the TSO can invest in the transmission line that connects nodes North and South.

Figure 8: Intra TSO model

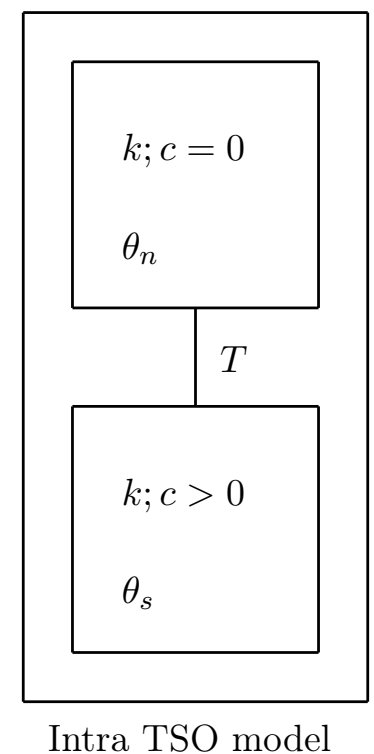


Figure 9: Benchmark model. Supplier n's outcome and profits
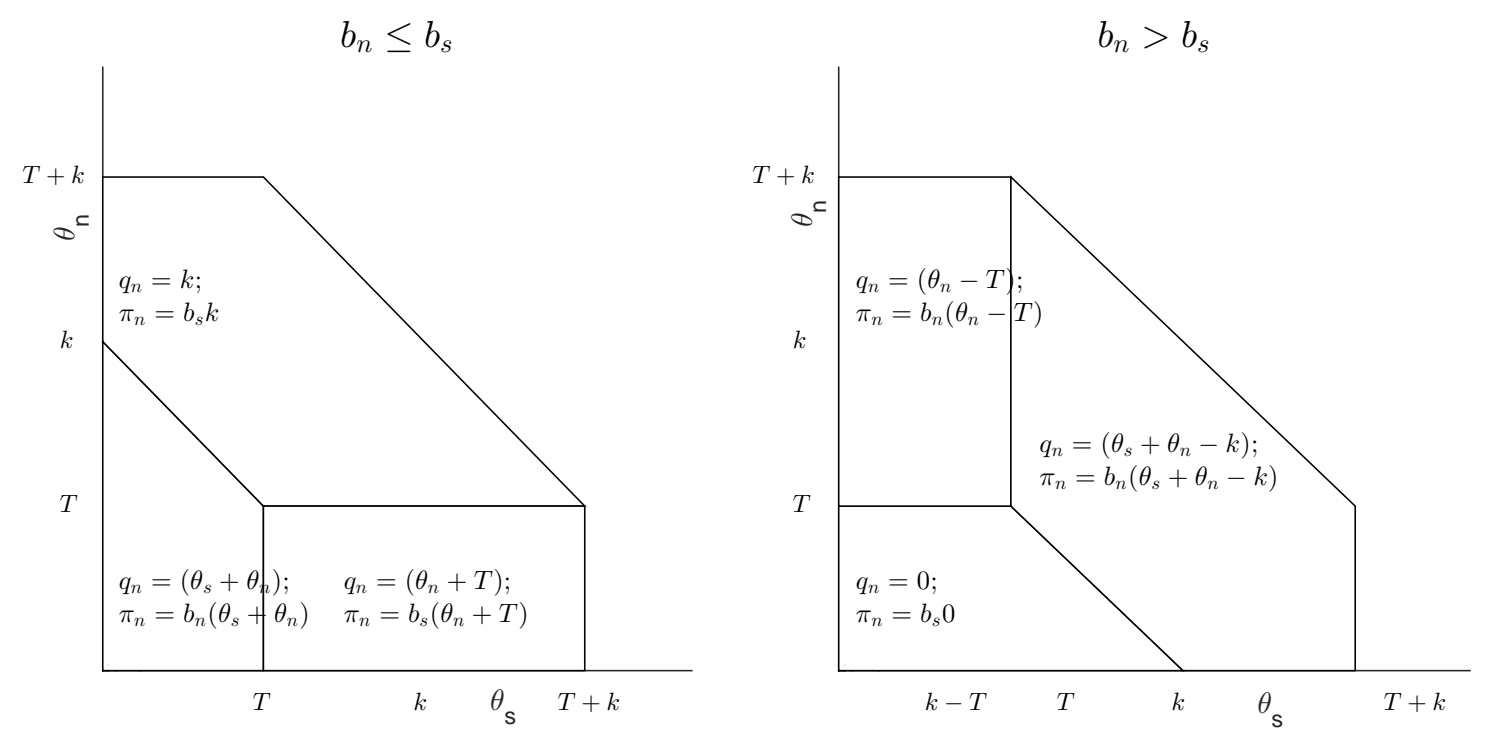

Timing of the game. First, I explain the imperfect competition case. The timing is the same as in the inter TSO investment model.

The output allocated to supplier $i, i=n, s$, denoted by $q_{i}(b ; \theta, T, k)$, is given by

$$
q_{i}(b ; \theta, T, k)= \begin{cases}\min \left\{\theta_{i}+\theta_{j}, \theta_{i}+T, k\right\} & \text { if } b_{i} \leq b_{j} \\ \max \left\{0, \theta_{i}-T, \theta_{i}+\theta_{j}-k\right\} & \text { if } b_{i}>b_{j}\end{cases}
$$

The output function plays an important role in determining the equilibrium and thus, I explain it in detail. Below, I describe the construction of supplier $n$ 's output function; the output for supplier $s$ is symmetric.$^{9}$

The demand that can be satisfied by supplier $n$ when it submits the lower bid $\left(b_{n} \leq b_{s}\right)$ is defined by $\min \left\{\theta_{s}+\theta_{n}, \theta_{n}+T, k\right\}$. The realization of $\left(\theta_{s}, \theta_{n}\right)$ determines three different areas (left-hand panel in figure 9). When demand in both nodes is low and the transmission line is not congested, supplier $n$ satisfies total demand $\left(\theta_{s}+\theta_{n}\right)$. If the demand in node South is larger than the transmission capacity $\theta_{s}>T$, supplier $n$ satisfies the demand in node South only up to the transmission capacity; therefore, the total demand that supplier $n$ can satisfy is $\left(\theta_{n}+T\right)$. When demand is high enough, supplier $n$ sells its entire production capacity $(k)$.

The demand that supplier $n$ satisfies when it submits the higher bid $\left(b_{n}>b_{s}\right)$ is defined by $\max \left\{0, \theta_{n}-T, \theta_{s}+\theta_{n}-k\right\}$. The realization of $\left(\theta_{s}, \theta_{n}\right)$ determines three different areas (right-hand panel in figure 9). When demand is low and the transmission line is not congested, supplier $s$ satisfies total demand and therefore, supplier $n$ 's residual demand is zero. As soon as the demand in node North is larger than the transmission capacity $\theta_{n}>T$, the demand in node North cannot be satisfied by supplier $s$ and thus, some residual demand $\left(\theta_{n}-T\right)$ remains for supplier $n$. When total demand is large enough, supplier $s$ cannot satisfy total demand, and some residual demand $\left(\theta_{s}+\theta_{n}-k\right)$ remains

\footnotetext{
${ }^{9}$ Supplier $s$ 's output function is symmetric except when there is a tie. In that case, supplier $s$ is dispatched last.
} 
for supplier $n$.

Finally, the payments are worked out by the auctioneer. When the auctioneer runs a uniform price auction, the price received by a supplier for any positive quantity dispatched by the auctioneer is equal to the higher bid accepted in the auction. Hence, for a given realization of $\theta \equiv\left(\theta_{j}, \theta_{i}\right)$ and a bid profile $b \equiv\left(b_{j}, b_{i}\right)$, supplier $i$ 's profits are expressed as

$$
\pi_{i}^{u}(b ; \theta, T, k)= \begin{cases}b_{i}\left(\theta_{i}+\theta_{j}\right) & \text { if } b_{i} \leq b_{j} \text { and }\left(\theta_{j} \leq T \text { and } \theta_{i}+\theta_{j} \leq k\right) \\ b_{j} \min \left\{\theta_{i}+T, k\right\} & \text { if } b_{i} \leq b_{j} \text { and }\left(\theta_{j}>T \text { or } \theta_{i}+\theta_{j}>k\right) \\ b_{j} 0 & \text { if } b_{i}>b_{j} \text { and }\left(\theta_{i} \leq T \text { and } \theta_{i}+\theta_{j} \leq k\right) \\ b_{i} \max \left\{\theta_{i}-T, \theta_{i}+\theta_{j}-k\right\} & \text { if } b_{i}>b_{j} \text { and }\left(\theta_{i}>T \text { or } \theta_{i}+\theta_{j}>k\right)\end{cases}
$$

Given the relevance of the payoff function determining the equilibrium. I explain it in detail. As with the outcome function, I focus on supplier $n$ 's payoff function; the one for supplier $s$ is symmetric.10 If $b_{n} \leq b_{s}$ and $\left(\theta_{s} \leq T\right.$ and $\left.\theta_{s}+\theta_{n} \leq k\right)$, supplier $n$ submits the lower bid in the auction, the transmission line is not congested and supplier $n$ has enough capacity to satisfy total demand; therefore, supplier $n$ sets the price and satisfies total demand. When $b_{n} \leq b_{s}$ and $\left(\theta_{s}>T\right.$ or $\left.\theta_{s}+\theta_{n}>k\right)$, supplier $n$ submits the lower bid in the auction, the transmission line is congested or supplier $n$ does not have enough capacity to satisfy total demand; therefore, supplier $s$ is called into operation, sets the price, and supplier $n$ sells its production capacity (up to the transmission line capacity) at the price set by supplier $s$ (left-hand panel, figure 9).

If $b_{n}>b_{s}$ and $\left(\theta_{n} \leq T\right.$ and $\left.\theta_{s}+\theta_{n} \leq k\right)$, supplier $n$ submits the higher bid in the auction, the transmission line is not congested and supplier $s$ has enough capacity to satisfy total demand; therefore, supplier $s$ sets the price and supplier $n$ 's residual demand is zero. When $b_{n}>b_{s}$ and $\left(\theta_{n}>T\right.$ or $\left.\theta_{s}+\theta_{n}>k\right)$, supplier $n$ submits the higher bid in the auction, the transmission line is congested or supplier $s$ does not have enough capacity to satisfy total demand; therefore, supplier $n$ is called into operation, sets the price and satisfies the residual demand (right-hand panel, figure 9).

In the perfect competition case. The suppliers submit a bid equal to their marginal cost. The efficient supplier (supplier $n$ ) is dispatched first, and its output is denoted by $q_{n}(b ; \theta, k, T)=\min \left\{\theta_{s}+\theta_{n}, \theta_{n}+T, k\right\}$. The inefficient supplier is dispatched last, and its output is denoted by $q_{s}(b ; \theta, k, T)=\max \left\{0, \theta_{s}-T, \theta_{s}+\theta_{n}-k\right\}$. Suppliers' profits are equal to:

$$
\begin{aligned}
& \pi_{n}(b ; \theta, k, T)= \begin{cases}b_{n}\left(\theta_{s}+\theta_{n}\right) & \text { if } \theta_{s} \leq T, \text { and } \theta_{s}+\theta_{n} \leq k \\
\left(b_{s} \text { or } P_{\Delta}^{*}\right) \min \left\{\theta_{n}+T, k\right\} & \text { otherwise }\end{cases} \\
& \pi_{s}(b ; \theta, k, T)= \begin{cases}b_{s} \max \left\{\theta_{s}-T, \theta_{s}+\theta_{n}-k\right\} & \text { if } \theta_{s}>T, \text { or } \theta_{s}+\theta_{n}>k \\
\left(b_{n} \text { or } P_{\Delta}^{*}\right)(0) & \text { otherwise }\end{cases}
\end{aligned}
$$

Given that supplier $n$ submits the lower bid, it is dispatched first and sets the price when it has enough production capacity to satisfy the demand, and when the transmission line that connects nodes North and South is not congested. Otherwise, suppliers $s$

\footnotetext{
${ }^{10}$ Supplier $s$ 's payoff function is symmetric except for the fact that it is necessary to subtract the production costs $(c)$.
} 
Figure 10: Intra TSO investment model. Equilibrium
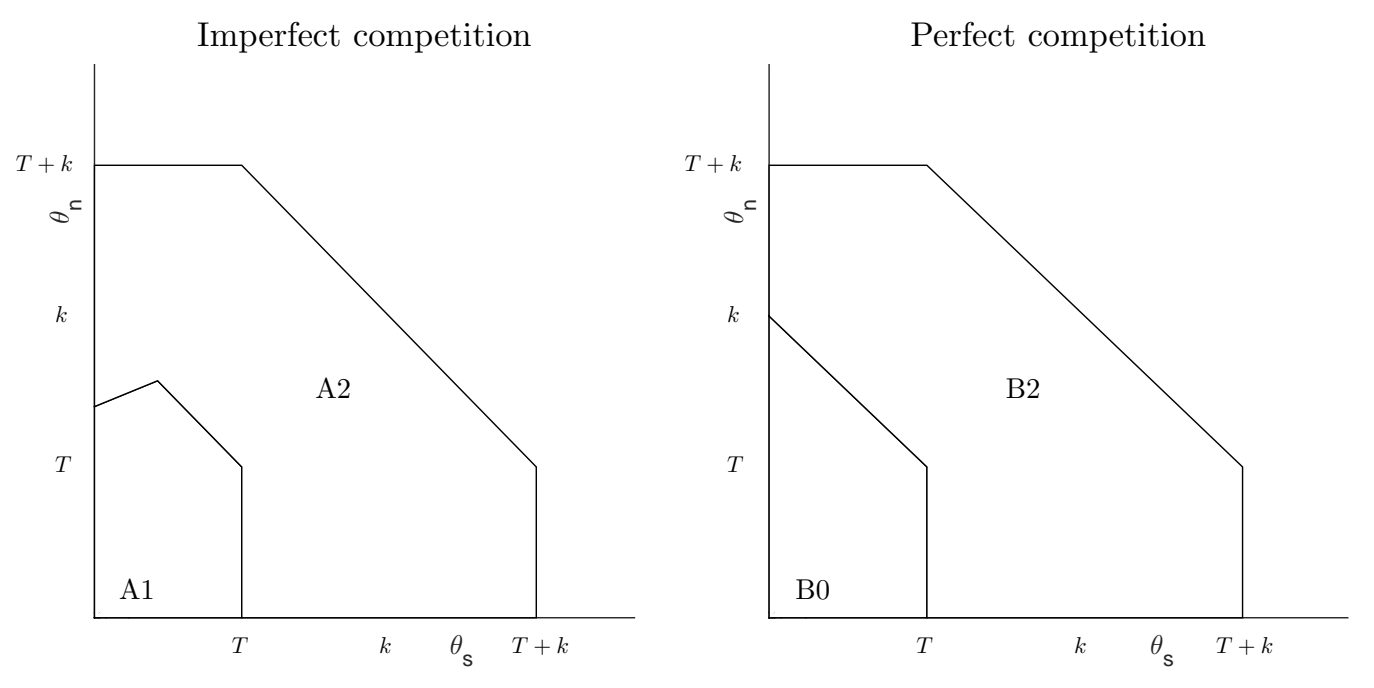

is called into operation setting the price, and satisfying the residual demand.

Equlibrium. First, I work out the equilibrium in the imperfect competition case. Using lemma one, I characterize the equilibrium.

Proposition 6. Intra TSO investment (imperfect competition case). The characterization of the equilibrium falls into one of the next two categories (left-hand upper panel, figure 10 .

i. Low-demand (area $A 1$ ). The equilibrium price is $c$.

ii. High-demand (area $A 2$ ). The equilibrium price is $P$.

When demand is low, both suppliers have enough production capacity to satisfy total demand, and the transmission line is not congested. Therefore, the suppliers compete fiercely to be dispatched first in the auction, and the efficient supplier submits a bid equal to $c$, extracting the efficiency rents and satisfying the demand in nodes North and South. When demand is high, at least one of the suppliers finds profitable to submit the maximum bid allowed by the auctioneer and satisfy the residual demand.

Proposition 7. Intra TSO investment (imperfect competition case). An increase in transmission capacity between nodes North and South increases the low-demand area (area $A 1$, figure 10.

An increase in transmission capacity has two different effects. First, it increases the competition between suppliers. Second, it increases suppliers' total demand. These two effects induce a decrease in equilibrium prices for two different reasons. First, if the suppliers want to be dispatched in the auction, the increase in competition forces them to decrease their bids. Second, the increase in demand makes it more attractive to submit low bids to be dispatched first in the auction, and to satisfy total demand. Therefore, an increase in transmission capacity between nodes North and South increases consumer welfare by increasing the low-demand area. 
Figure 11: Equilibrium comparison
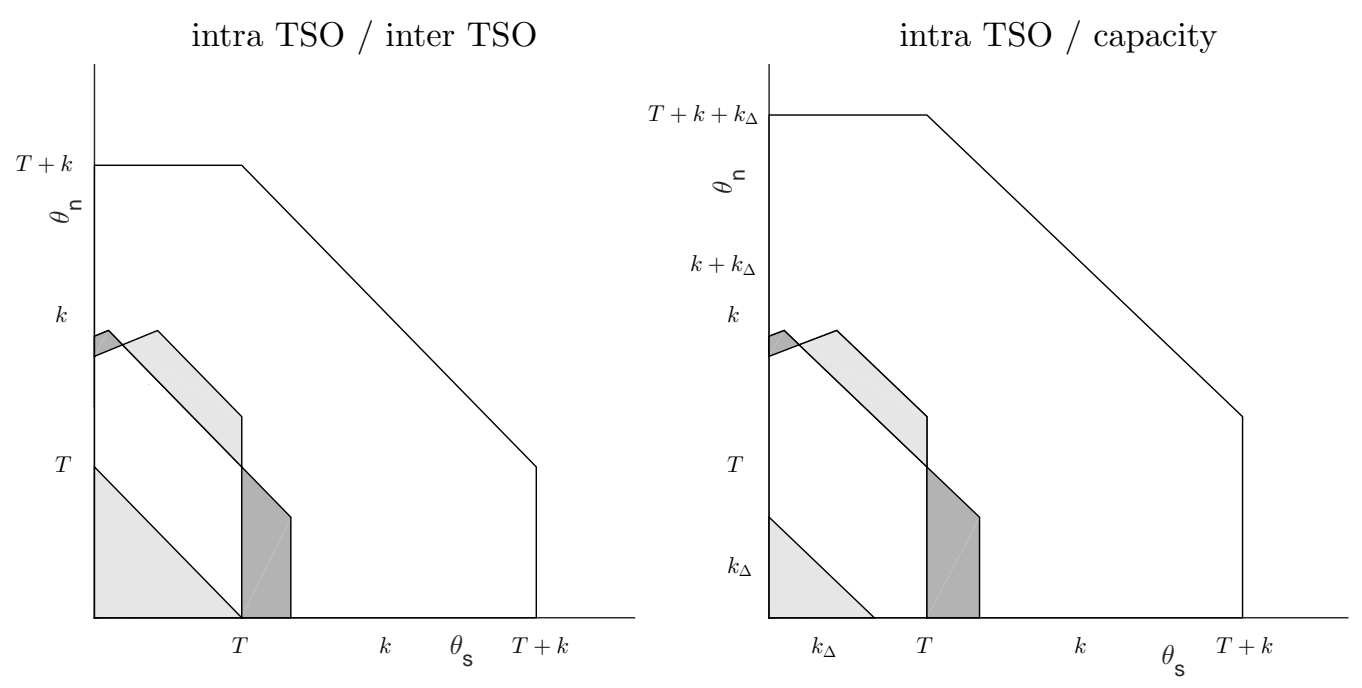

I characterize the equilibrium in the perfect competition case.

Proposition 8. Intra TSO investment model (perfect competition). The characterization of the equilibrium falls into one of the next three categories (right-hand panel, figure 6).

i Low-demand (area $B 0$ ). The equilibrium price is 0 .

ii High-demand (area B2). The equilibrium price is $c$.

In the perfect competition case, the suppliers submit bids equal to their marginal costs. When the demand is low, the efficient supplier has enough production capacity to satisfy total demand, and the transmission line that connects node North with zone Delta is not congested, the efficient supplier satisfies the demand in nodes North, South, and the equilibrium price is 0 . When the demand is high, the efficient supplier does not have enough production capacity to satisfy total demand, or the transmission line that connects nodes North and South is congested, the inefficient supplier is called into operation, and the equilibrium price is $c$.

Equilibrium comparison. It is enough to compare equations 1 and 5 with equation 11 , and equations 2 and 6 with equation 11 .

First, I compare the intra TSO investment model and the inter TSO investment model (left-hand panel, figure 11). An increase in transmission capacity between nodes increases the competition between both suppliers; in contrast, an increase in transmission capacity from an outside zone increases the competition only in node North. Moreover, an increase in transmission capacity from an outside zone only increases supplier $n$ 's total demand. Therefore, an intra TSO transmission investment mainly increases consumer welfare in node South (dark gray area); in contrast, an inter TSO transmission investment increases consumer welfare mainly in node North (light gray area).

Second, I compare the intra TSO investment model with the production capacity investment model (right-hand panel, figure 11). The comparison is straightforward following 
the previous explanations.

Following the same argument, it cannot be established a dominance rank between models in terms of suppliers' profits.

Therefore, it is not possible to establish a rank between models in terms of consumers welfare and suppliers' profits since the inter TSO investment model or the production capacity investment model perform better than the intra TSO investment model for a particular demand range, but they perform worse for another particular demand range. However, knowing the load curve, and so the realization of demand, a clear comparison between models in terms of consumer welfare and suppliers' profits can be established.

\section{Intra TSO investment model. Proofs}

\section{Proposition 6.}

By lemma one, the equilibrium price could be $c$, or $P$; where $(c<P)$. The equilibrium price is $c$ when the efficient supplier has enough production capacity to satisfy total demand, the transmission line is not congested, and it prefers to undercut the inefficient supplier and satisfy total demand. The equilibrium price is $P$ when at least one supplier finds profitable to submit the maximum bid allowed by the auctioneer and satisfy the residual demand. Therefore, to characterize the equilibrium, it is necessary to work out the demand values $\left(\theta_{s}, \theta_{n}\right)$ for which each supplier prefers to set a price equal to $c$, or $P$.

First, the efficient supplier ( $\operatorname{supplier} n$ ) prefers to submit a low bid and satisfy total demand when:

$$
\begin{aligned}
P \max \left\{0, \theta_{n}-T, \theta_{s}+\theta_{n}-k\right\} & <c \min \left\{\theta_{s}+\theta_{n}, \theta_{n}+T, k\right\} \Leftrightarrow \\
P\left(\theta_{n}-T\right) & <c \min \left\{\theta_{s}+\theta_{n}, k\right\}, \theta_{s} \leq T \\
P\left(\theta_{s}+\theta_{n}-k\right) & <c \min \left\{\theta_{n}+T, k\right\}, \theta_{s}>T
\end{aligned}
$$

Doing some algebra,

$$
\begin{aligned}
\theta_{n}(P-c)<P T+c \theta_{s} \Leftrightarrow \theta_{n} & <\frac{P T}{P-c}+\frac{c \theta_{s}}{P-c}, \theta_{s} \leq T, \text { and } \theta_{n}+\theta_{s} \leq k \\
P\left(\theta_{n}-T\right)<c k \Leftrightarrow \theta_{n} & <T+\frac{c k}{P}, \theta_{s} \leq T, \text { and } \theta_{n}+\theta_{s}>k \\
(P-c)\left(\theta_{n}\right)<P k+c T-P \theta_{s} \Leftrightarrow \theta_{n} & <\frac{P k+c T-P \theta_{s}}{P-c}, \theta_{s}>T, \text { and } \theta_{n}+\theta_{s} \leq k \\
P\left(\theta_{n}+\theta_{s}-k\right)<c k \Leftrightarrow \theta_{n} & <k+\frac{c k}{P}-\theta_{s}, \theta_{s}>T, \text { and } \theta_{n}+\theta_{s}>k
\end{aligned}
$$

Second, the inefficient supplier (supplier $s$ ) prefers to submit a low bid and satisfy total demand when: 


$$
\begin{array}{r}
(P-c) \max \left\{0, \theta_{s}-T, \theta_{s}+\theta_{n}-k\right\}<(c-c) \min \left\{\theta_{s}+\theta_{n}, \theta_{s}+T, k\right\} \\
(P-c)\left(\theta_{s}+\theta_{n}-k\right)<(c-c)\left(\theta_{s}+\theta_{n}\right), \theta_{s} \leq T \Leftrightarrow \\
\theta_{n}<k-\theta_{s}, \theta_{s} \leq T \\
(P-c)\left(\theta_{s}-T\right)<(c-c) \min \left\{\theta_{s}+\theta_{n}, k\right\} \theta_{s}<T .
\end{array}
$$

The inequality never holds when $\theta_{s}>T$.

Finally, the intersection of the areas defined by equations 11 and 12 defines the lowdemand equilibrium area (area $A 1$, left-hand panel in figure 10). Any combination of demands $\left(\theta_{s}, \theta_{n}\right)$ outside that area defines the high-demand equilibrium area (area $A 2$, left-hand upper panel in figure 10 .

In the low-demand area, the equilibrium is $b_{s}^{*}=b_{n}^{*}=c$. In the high-demand area, the equilibrium is

$$
\begin{array}{r}
\left(b_{s} *=P, b_{n}^{*} \in\left[0, c+\frac{(P-c) \max \left\{\theta_{s}-T, \theta_{s}+\theta_{n}-k\right\}}{\min \left\{\theta_{s}+\theta_{n}, \theta_{s}+T, k\right\}}\right]\right), \text { or } \\
\left(b_{s} * \in\left[0, \frac{P \max \left\{\theta_{n}-T, \theta_{s}+\theta_{n}-k\right\}}{\min \left\{\theta_{s}+\theta_{n}, \theta_{n}+T, k\right\}}\right], b_{n}^{*}=P\right) .
\end{array}
$$

In the low-demand area (area $A 0)$, suppliers' profits are $\pi_{s}^{*}=0, \pi_{n}^{*}=c\left(\theta_{s}+\theta_{n}\right)$. In the high-demand area, depending on the equilibrium (equation 13), suppliers' profits are $\pi_{s}^{*}=(P-c) \max \left\{\theta_{s}-T, \theta_{s}+\theta_{n}-k\right\}, \pi_{n}^{*}=P \min \left\{\theta_{n}+T, k\right\} ;$ or $\pi_{s}^{*}=$ $(P-c) \min \left\{\theta_{s}+T, k\right\}, \pi_{n}^{*}=P \max \left\{\theta_{n}-T, \theta_{s}+\theta_{n}-k\right\}$.

Proposition 7. An increase in transmission capacity modifies equations 11 and 12 , increasing area $A 1$.

Proposition 8. The proof is as in proposition 2. 


\section{References}

Bjørndal, M., and Jørnsten K., 2001, "Zonal Pricing in a Deregulated Electricity Market," The Energy Journal, 22, 51-73.

Bjørndal, M., and Jørnsten K., 2007, "Benefits from Coordinating Congestion ManagementThe Nordic Power Market," Energy Policy, 35, 1978-1991.

Bohn, R., Caramanis M. and Schweppe F., 1984, "Optimal Pricing in Electrical Networks over Space and Time," RAND Jounal of Economics, 3, 15.

Borenstein, S., Bushnell J. and Stoft S., 2000, "The Competitive effects of transmission capacity in a deregulated electricity industry," Rand Journal of Economics, 31, 294-325.

Chao, H-P., and Peck S., 1996, "A Market Mechanism for Electric Power Transmission," Journal of Regulatory Economics, 1, 25-59.

Commission Regulation (EU), 2015/1222, "Establishing a Guideline on Capacity Allocation and Congestion Management," Official Journal of the European Union.

Deneckere, R., and Kovenock D., 1996, "Bertrand-Edgeworth Duopoly with Unit Cost Asymmetry," Economic Theory, 8, 1-25.

Dijk, J., and Willems W., 2011, "The effect of counter-trading on Competition in Electricity Markets," Energy Policy, 23, 1764-1773.

Energinet, 2015, "System Plan 2015. Electricity and Gas in Denmark."

Ehrenmann, A., and Smeers Y., 2005, "Inefficiencies in European Congestion Management Proposals," Utilities Policy, 13, 135-152.

ENTSO-E, 2010, "ENTSO-E Impact of Increased Amounts of Renewable Energy on Nordic Power System Operation."

ENTSO-E, 2014, "10-Year Network Development Plan."

European Commission, 2013, "Commission Regulation (EU) No 347/2013. On Guidelines for Trans-European Energy Infrastructure and Repealing Decision No 1364/2006/EC and amending Regulation (EC) No 713/2009, (EC) No 714/2009 and (EC) No 715/2009."

European Commission, 2015, "Options for Future European Electricity System Operation."

Escobar, J.F., and Jofré A., 2010, "Monopolistic Competition in Electricity Networks with Resistance Losses," Economic Theory, 44, 101-121.

EWIS, 2010, "Towards a Successful Integration of Large Scale Wind Power into European Electricity Grids." 
Fabra, N., von der Fehr N. H. and Harbord D., 2006, "Designing Electricity Auctions," Rand Journal of Economics, 37, 23-46.

von der Fehr, N.H., and Harbord D., 1993, "Spot Market Competition in the UK Eletricity Industry," Economic Journal, 103, 531-46.

Green, R., 2007, "Nodal Pricing of Electricity: How Much Does It Cost to Get It Wrong?," Journal of Regulatory Economics, 31, 125-149.

Green, R., 2010, "Are the British Electricity Trading and Transmission Arrangements Future-Proof?," Utilities Policy, 18, 186-194.

Green, R., and Vasilakos N., 2010, "Market Behaviour with Large Amounts of Intermittent Generation," Energy Policy, 38, 3211-3220.

Grimm, V., Martin A., Schmidt M., Weibelzahl M., and Zöttl G., 2016, "Transmission and Generation Investment in Electricity Markets: The Effects of Market Splitting and Network Fee Regimes," European Journal of Operational Research, 254, 493-509.

Hogan, W., 1992, "Contract Networks for Electric Power Transmission," Journal of Regulatory Economics, 4, 211-242.

Holmberg, P., and Philpott A.B., 2012, "Supply Function Equilibria in Transportation Networks," IFN working paper 945.

Holmberg, P., and Lazarczyk E., 2015, "Comparison of Congestion Management Techniques: Nodal, Zonal and Discriminatory Pricing," The Energy Journal, 36, 145-166.

Joskow, P. L., Tirole J., 2000, "Transmission rights and market power on electric power networks," RAND Journal of Economics, 31, 450-487.

Leuthold, F., Rumiantseva I., Weigt H., Jeske T., and von Hirschhausen C., 2005, "Nodal Pricing in the German Electricity Sector -A Welfare Economics Analysis, with Particular Reference to Implementing Offshore Wind Capacities," Electricity Markets Working Papers, WP-EM-08a.

Neuhoff, K., Barquin J., Boots M.G., Ehrenmann A., Hobbs B.F., Rijkers F.A.M., and Vázquez M., 2005, "Network-Constrained Cournot Models of Liberalized Electricity Markets: the Devil is in the Details," Energy Economics, 27, 495-525.

Neuhoff, K., Boyd T., Grau T., Echebarren F., Bialek J., Dent D., von Hirschhausen C., Hobbs B., Kunz F., Weigt H., Nabe C., Papaefthymiou G., and Weber C., 2011, "Renewable Electricity Energy Integration: Quantifying the Value of Design of Markets for International Transmission Capacity," DIW Berlin Discussion Papers, 1166.

Newbery, D., Strbac G., and Viehoff I., 2015, "The Benefits of Integrating European Electricity Markets," EPRG Working Paper, 1504. 
Stoft, S., 1998, "Using Game Theory to Study Market Power in Simple Networks," Federal Energy Regulatory Commission. Washington, D.C.

Svenska Kraftnät, 2015, "Network Development Plan 2016-2025."

Wu, F., Pravin V., Pablo S., and Shmuel O., 1996, "Folk Theorems on Transmission Access: Proofs and Counterexamples," Journal of Regulatory Economics, 10, 5-23. 